\title{
1 Maladaptive myelination promotes epileptogenesis in absence epilepsy
}

2 Juliet K. Knowles ${ }^{1}$, Caroline Soane ${ }^{1}$, Eleanor Frost ${ }^{1}$, Lydia T. Tam ${ }^{1}$, Danielle Fraga ${ }^{1}$, Haojun Xu , 3 Ankita Batra ${ }^{1}$, Lijun $\mathrm{Ni}^{1}$, Katlin Villar ${ }^{1}$, Tristan Saucedo ${ }^{1}$, John Huguenard ${ }^{1 *}$, Michelle Monje ${ }^{1 *}$

1. Department of Neurology and Neurological Sciences, Stanford University, Stanford, California USA 94305

${ }^{*}$ co-corresponding

Please address correspondence to:

10 Michelle Monje MD PhD

11265 Campus Drive, G3077

12 Stanford, CA 94305

13 mmonje@stanford.edu

and

John Huguenard, PhD

john.huguenard@stanford.edu

19 Stanford Neurosciences Building

20290 Jane Stanford Way

21 Stanford, CA 94305

\section{Summary}

25 Neuronal activity can influence the generation of new oligodendrocytes (oligodendrogenesis) and

26 myelination. In health, this is an adaptive process that can increase synchrony within distributed

27 neuronal networks and contribute to cognitive function. We hypothesized that in seizure disorders,

28 aberrant neuronal activity may promote maladaptive myelination that contributes to pathogenesis.

29 Absence epilepsy is a disease defined by increasingly frequent behavioral arrest seizures over

30 time, thought to be due to thalamocortical network hypersynchrony. We tested the hypothesis that

31 activity-dependent myelination resulting from absence seizures promotes epileptogenesis. Using

32 two distinct models of absence epilepsy, Wag/Rij rats and Scn8a ${ }^{+/ m u t}$ mice, we found increased

33 oligodendrogenesis and myelination specifically within the absence seizure network. These

34 changes are evident only after seizure onset in both models and are prevented with

35 pharmacological inhibition of seizures. Genetic blockade of activity-dependent myelination during

36 epileptogenesis markedly decreased seizure frequency in the $S c n 8 a^{+/ m u t}$ mouse model of absence 
epilepsy. Taken together, these findings indicate that activity-dependent myelination driven by absence seizures contributes to seizure kindling during epileptogenesis.

\section{Introduction}

41 Neuronal activity can modulate myelin development (Makinodan et al., 2012; Hines et al., 2015;

Mensch et al., 2015) and promote new oligodendrocyte generation and myelination in cortical and callosal axons throughout life (Liu et al., 2012; Gibson et al., 2014; Hughes et al., 2018; Mitew et al., 2018; Swire et al., 2019; Steadman et al., 2020). Activity-regulated myelination is adaptive in the healthy brain, increasing neural network synchrony (Pajevic et al., 2014; Noori et al., 2020; Steadman et al., 2020) and contributing to cognitive functions including learning, attention and memory consolidation (McKenzie et al., 2014; Xiao et al., 2016; Geraghty et al., 2019; Steadman et al., 2020). The effects of myelin plasticity on network function in health raises the question of how activity-regulated myelination may modulate network function in disease states characterized by abnormal patterns of neuronal activity, such as epilepsy. Diffusion tensor imaging (DTI) has demonstrated abnormal white matter microstructure in various forms of epilepsy including absence epilepsy in humans and rodent models; however, definitive conclusions cannot be drawn about underlying white matter structure, nor is it known how altered white matter structure may contribute to epilepsy pathophysiology (Chahboune et al., 2009; Gross, 2011; Yang et al., 2012; van Luijtelaar et al., 2013; Weiskopf et al., 2015).

Absence seizures occur in multiple forms of human epilepsy, and are associated with behavioral arrest and generalized but frontally predominant 3-4 Hz spike-wave discharges (Dlugos et al., 2013; Guilhoto, 2017). Seizures arise from abnormal oscillations between the thalamus and cortex and propagate along myelinated tracts including the anterior portions of the corpus

61 callosum (Musgrave and Gloor, 1980; Vergnes et al., 1989; Holmes et al., 2004). In humans and 62 rodents, absence seizures are brief but very frequent, occurring hundreds of times per day 
63 (Coenen and Van Luijtelaar, 1987). Thus, absence epilepsy presents an ideal paradigm to examine the relationship between activity-regulated myelination and seizure pathophysiology.

Rodent models of absence epilepsy exhibit defined periods of epileptogenesis in which seizures begin and then increase in daily frequency over time (Coenen and Van Luijtelaar, 1987; Dezsi et al., 2013; Makinson et al., 2017). This pattern of developmental seizure onset with rapid, progressive worsening over time reflects the natural history of untreated absence epilepsies in children (Brigo et al., 2018). Blockade of seizures during this window in one model of absence epilepsy, Wag/Rij rats, prevents or delays epileptogenesis (Blumenfeld et al., 2008; van Luijtelaar et al., 2013; Leo et al., 2019), indicating that seizure onset induces pathological network changes that contribute to subsequent progression in seizure frequency (kindling). While mechanisms of absence seizure kindling are incompletely understood, a common feature is excessive synchrony (coordinated firing of groups of neurons) in the thalamocortical network (Huntsman et al., 1999; regulated myelination on network synchrony (Noori et al., 2020; Steadman et al., 2020), we hypothesized that abnormally increased myelination induced by seizures might contribute to increasing seizure frequency during epileptogenesis.

Results

\section{Oligodendrogenesis increases within the absence seizure network after seizure onset}

84 To test the putative relationship between absence seizures and myelination, we used a well85 established model of absence epilepsy, Wag/Rij rats (Coenen and Van Luijtelaar, 1987;

86 Blumenfeld et al., 2008; Russo et al., 2016; Sorokin et al., 2017; Citraro et al., 2020). Wag/Rij is

87 an inbred rat strain that develops spontaneous, stereotyped absence seizures characterized by

88 brief behavioral arrest, similar to the episodes that occur in children with absence epilepsy (Wirrell, 
2003; Russo et al., 2016). The EEG correlate of these episodes in Wag/Rij rats are $\sim 8 \mathrm{~Hz}$, generalized, frontally predominant spike-wave discharges that are maximal in the somatosensory cortices (Coenen and Van Luijtelaar, 2003; van Luijtelaar and Sitnikova, 2006). Absence seizures arise from connections between the thalamus and the cortex (Williams, 1953; Masterton et al., 2013; Tenney et al., 2013; McCafferty et al., 2018). In rodents, absence seizures are particularly prominent in relays between the ventrobasal nuclear complex of the thalamus and somatosensory cortex, driven by complex circuitry involving interneurons of the reticular thalamic nucleus (Kao and Coulter, 1997; Meeren et al., 2002; Fogerson and Huguenard, 2016; Makinson et al., 2017). Seizures propagate throughout the brain via myelinated tracts including the internal capsule (interconnects the thalamus and cortex) and the corpus callosum, a commissural tract which is required for seizure generalization (Musgrave and Gloor, 1980; Vergnes et al., 1989) (Figure 1A). Seizures in Wag/Rij rats develop over a well-defined period of epileptogenesis: infrequent

101 seizures begin around 2 months of age and steadily increase in daily frequency until around 6 102 months of age, when the rate plateaus at 20-30 seizures per hour (Blumenfeld et al., 2008; van

103 Luijtelaar et al., 2013). A closely related rat strain from which Wag/Rij is derived, Wistar, does not 104 typically develop absence seizures during this time frame and therefore is used as a control for 105 Wag/Rij (Blumenfeld et al., 2008; Chahboune et al., 2009; Sarkisova et al., 2010).

107 To investigate whether absence seizures cause aberrant activity-regulated myelination within the 108 seizure network, we began by assessing oligodendrocyte precursor cell (OPC) proliferation 109 together with total numbers of OPCs and mature oligodendrocytes in the mid-region (body) of the 110 corpus callosum, focusing specifically on the area interconnecting the somatosensory cortices 111 that is involved in the absence seizure network. Given the anatomical differences between $112 \mathrm{Wag} / \mathrm{Rij}$ and Wistar (control) rats (Supplemental Figure 1A-B), we utilized unbiased 113 stereological methods to assess total cell numbers as well as volume of the corpus callosum and 114 cell density. Prior to seizure onset, at 1.5 months of age, control rats and Wag/Rij (seizure) rats 
115 have equivalent numbers of callosal OPCs. However, at 6 months of age, when seizures are well

116 established, we found that Wag/Rij rats exhibit a significant increase in OPC (cells co-expressing

117 PDGFR $\alpha$ and Olig2) number and density (Figure 1B and Supplemental Figure 1C) as well as

118 dividing (Ki67 positive) OPCs (Figure 1C). We next determined whether increased numbers of

119 precursor cells were associated with increased quantities of callosal oligodendrocytes (CC1,

120 Olig2-expressing cells) in the same region of the corpus callosum. Wag/Rij rats also exhibit

121 increased oligodendrocytes (total number and cell density) at 6 months of age, following the

122 period of epileptogenesis, indicative of increased oligodendrogenesis (Figure 1D and

123 Supplemental Figure 1D). In contrast, Wag/Rij and control rats exhibit similar numbers of

124 oligodendrocytes at 1.5-months of age, prior to seizure onset (Figure 1D). Taken together, these

125 data indicate that oligodendrogenesis increases within the seizure circuit in parallel with

126 epileptogenesis in the Wag/Rij rat model of absence epilepsy.

\section{Myelination increases within corpus callosum regions affected by absence seizures}

129 Given that epileptogenesis is associated with increased callosal oligodendrogenesis in Wag/Rij 130 rats, we next investigated whether myelin structure is also altered. We utilized transmission 131 electron microscopy to visualize cross sections of myelinated axons in the mid-sagittal plane of 132 the body of the corpus callosum (Figure 2A), where oligodendrogenesis was assessed. We 133 measured myelin sheath thickness per axon diameter, g-ratio (Gibson et al., 2014; Geraghty et 134 al., 2019; Steadman et al., 2020) in 1.5- and 6-month old Wag/Rij rats and Wistar controls. We

135 found an increase in mean myelin sheath thickness (decreased g-ratio) in 6-month-old Wag/Rij

136 rats compared to controls (Figure 2B, D). This difference in myelin was not observed prior to 137 seizure onset at 1.5 months (Figure 2B, C) and is not attributable to strain differences in axon 138 diameter (Supplemental Figure 2A). 
140 Absence seizures in rodents are most prominent in the somatosensory cortices (Meeren et al.,

141 2002; Polack et al., 2007; Scicchitano et al., 2015). We reasoned that if abnormally increased

142 myelination is caused by seizure activity, these changes would be specific to the seizure-affected

143 regions. We therefore assessed myelin in the posterior corpus callosum (splenium), connecting

144 cortical regions where seizure activity is less prominent in humans and rodents (Meeren et al.,

145 2002; Nersesyan et al., 2004; Moeller et al., 2010; Tenney et al., 2013; Meyer et al., 2018). The

146 seizure-associated myelin difference observed in the body of the corpus callosum was not found

147 in the splenium; Figure 2E-G. Taken together, these data indicate that seizures are associated

148 with increased oligodendrogenesis and abnormally increased myelination in an anatomical 149 pattern that parallels seizure activity.

151 Seizures are necessary for aberrant callosal myelination

152 The temporal association between epileptogenesis and abnormally increased

153 oligodendrogenesis and myelination suggests that seizures may induce aberrant activity154 regulated myelination in Wag/Rij rats. In order to determine whether seizures are required for the 155 observed increases in oligodendrogenesis and myelination, we treated Wag/Rij and control rats 156 with the anti-seizure drug ethosuximide (ETX) at $\sim 300 \mathrm{mg} / \mathrm{kg} / \mathrm{day}$, a dose known to prevent or 157 reduce seizures in Wag/Rij rats (Blumenfeld et al., 2008; Sarkisova et al., 2010). Similar to 158 published work, this led to a mean plasma concentration of $101.3 \pm 10.33$ micrograms per $\mathrm{mL}$ 159 (mean \pm SEM, $\mathrm{n}=20$ rats), without signs of toxicity (Blumenfeld et al., 2008) and similar to 160 therapeutic levels in humans, typically between 40-100 micrograms per mL 161 (https://pubchem.ncbi.nlm.nih.gov/compound/Ethosuximide). Treatment was initiated at 1.5 162 months of age, prior to seizure onset. Following 5 months of treatment, EEG at 6.5 months of age 163 revealed frequent absence seizures in vehicle-treated Wag/Rij rats (Figure 3A-B). Consistent 164 with prior published data (Blumenfeld et al., 2008), mean seizure duration in vehicle-treated 
165 Wag/Rij rats was $5 \pm 0.5$ seconds (mean \pm SEM, $n=6$ rats). As expected, treatment with ETX over

166 the period of epileptogenesis significantly decreased or prevented seizures (Figure 3B).

168 We examined callosal OPC number and myelination from control or Wag/Rij hemi-brains following 169 vehicle or ETX administration at 7 months of age. Similar to the findings described above (Figures

170 1, 2), OPC number and myelin sheath thickness were increased in vehicle-treated 7-month-old

171 Wag/Rij rats compared to controls. However, ETX treatment normalized OPC number and myelin 172 sheath thickness (g-ratio) in Wag/Rij rats (Figure $3 \mathbf{C}-\mathbf{F}$ ). ETX did not influence axonal diameter

173 (Supplemental Figure 2B).

175 Together, these findings indicate that seizures increase myelination specifically within the seizure176 affected region and suggest a mechanism of aberrantly increased activity-dependent myelination

177 that could be deleterious (maladaptive), contributing to epilepsy pathogenesis. To further test this 178 hypothesis, we sought to evaluate seizure-related myelin changes in a second model of absence 179 epilepsy.

181 Increased oligodendrogenesis and myelination in Scn8a ${ }^{+/ m u t}$ mice

182 We next quantified oligodendrogenesis and myelin structure in a second, distinct rodent model of 183 absence epilepsy, Scn8a $a^{+/ m u t}$ mice. The use of this mouse model confers the advantage of wild184 type littermates on a congenic background, and the opportunity for targeted genetic manipulation 185 of activity-dependent myelination. Scn $8 a^{+/ m u t}$ mice bear a heterozygous loss of function mutation 186 in the voltage-gated sodium channel Nav1.6, which results in abnormal thalamocortical hyper187 synchrony and spontaneous 4-8 Hz absence seizures (Papale et al., 2009; Makinson et al., 2017). $188 \mathrm{Scn}_{8 \mathrm{a}^{+/ m u t}}$ mice exhibit seizures that begin around post-natal day (P)21 and steadily increase in 189 frequency until they occur 20-30 times per hour, by P35-P45 (Makinson et al., 2017). 
191 We assessed callosal OPC proliferation and number in Scn8a ${ }^{+/ m u t}$ mice and littermate wild-type

192 control mice $\left(\right.$ Scn8a $\left.{ }^{+/+}\right)$before (P21) and after (P45) seizures are well established. Prior to seizure

193 onset, callosal OPC proliferation and total number of callosal OPCs were equivalent. In contrast,

194 after seizures are well established at P45, we found increased overall numbers of OPCs and

195 proliferating OPCs in the corpus callosum of $S c n 8 a^{+/ m u t}$ animals relative to littermate controls

196 (Figure 4A-D). While corpus callosum volume was equivalent in Scn8a ${ }^{+/ m u t}$ and littermate control

197 mice at P21, the volume of the corpus callosum was increased in Scn8a ${ }^{+/ m u t}$ mice at P45

198 (Supplemental Figure 3A), Concordant with previous work demonstrating constant density of OPCs throughout the murine brain (Hughes et al., 2013), we found that OPC density was similar in both groups when normalized to corpus callosum volume (Supplemental Figure 3B). The total number and callosal density of mature oligodendrocytes were found to be equivalent at P21, but increased in Scn8a ${ }^{+/ m u t}$ mice relative to $S c n 8 a^{+/}$at P45, indicative of increased oligodendrogenesis after seizure onset (Figure 4E-F, Supplemental Figure 3C).

205 The observed increase in corpus callosum volume after seizure onset (Supplemental Figure 3A) 206 could be consistent with increased myelination. To determine whether increased 207 oligodendrogenesis in $S c n 8 a^{+/ m u t}$ mice is associated with increased myelination, we again 208 assessed myelin structure in the midline sagittal body of the corpus callosum (Figure 5). This 209 revealed that myelin sheath thickness was increased after seizure onset at P45 in Scn8a ${ }^{+/ m u t}$ mice 210 relative to Scn8a $^{+/+}$littermate controls (Figure 5A-B, D). Prior to seizure onset at P21, g-ratios 211 were equivalent in Scn8a ${ }^{+/ m u t}$ and littermate control mice. (Figure 5A-C). Mean myelinated axon 212 diameter was equivalent at P21 and at P45 in $S c n 8 a^{+/ m u t}$ mice relative to $S c n 8 a^{+/+}$littermate 213 controls, indicating that altered axon size does not contribute to $g$-ratio differences (Figure 5F). 214 Normalizing to differences in callosal volume, myelinated axon number was increased in P45

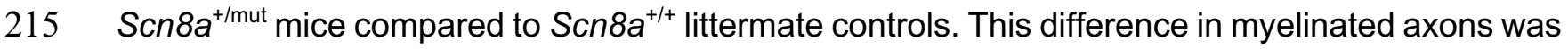
216 not present prior to epileptogenesis at P21 (Figure 5E). 
218 Taken together, findings in both Wag/Rij rat and Scn8a ${ }^{+/ m u t}$ mouse models demonstrate that

219 absence seizures induce abnormally increased myelination within the affected thalamocortical

220 seizure network. We next sought to determine the functional impact of seizure-associated

221 myelination and tested the hypothesis that aberrantly increased myelination contributes to

222 disease pathogenesis.

223

224 Activity-dependent myelination contributes to epileptogenesis

225 In the healthy brain, activity-dependent myelination functions to synchronize regions within

226 distributed neuronal networks, and this process is required for multiple forms of learning (Gibson

227 et al., 2014; McKenzie et al., 2014; Xiao et al., 2016; Geraghty et al., 2019; Noori et al., 2020;

228 Pan et al., 2020; Steadman et al., 2020). We hypothesized that seizure-associated, abnormally

229 increased myelination might contribute to thalamocortical network hypersynchrony during

230 epileptogenesis (Makinson et al., 2017), increasing disease severity. To assess the functional

231 impact of myelin plasticity in absence epilepsy, we sought to block activity-dependent myelination

232 during the period of epileptogenesis. We recently demonstrated that activity-dependent secretion

233 of Brain Derived Neurotrophic Factor (BDNF) (Balkowiec and Katz, 2000; Hartmann et al., 2001;

234 Dieni et al., 2012), and its subsequent signaling through the TrkB receptor on OPCs, is required

235 for activity-dependent myelination of corticocallosal projection neurons (Geraghty et al., 2019).

236 Conditional deletion of TrkB from OPCs prevents activity-dependent myelination in the corpus

237 callosum but does not alter homeostatic oligodendrogenesis nor lead to myelin loss (Geraghty et 238 al., 2019).

240 To enable blockade of activity-dependent myelination during epileptogenesis in Scn8a ${ }^{+/ m u t}$ mice, 241 we generated $S c n 8 a^{+/ m u t}$ and $S c n 8 a^{+/+}$littermates with floxed TrkB receptors (Scn8a ${ }^{+/ m u t} ;$ TrkB $B^{\text {fl/fl }}$

242 and $\left.S c n 8 a^{+/+} ; \operatorname{TrkB}{ }^{f / / f l}\right)$. These mice were crossed with mice that express Cre under the PDGFR $\alpha$ 
243 promoter, in OPCs (Hughes et al., 2013)), following the administration of tamoxifen (TrkB ${ }^{\mathrm{fl} / \mathrm{fl} \text {; }}$

244 PDGFR $\alpha:$ :Cre-ER). Induction of Cre in this model leads to TrkB deletion in about $80 \%$ of OPCs

245 (Geraghty et al., 2019); leak of Cre expression is not found in neurons (Mount et al., 2019). This 246 cross yielded Scn8a $a^{+/ m u t} ; \operatorname{TrkB}{ }^{f / / f l}$ and $S c n 8 a^{+/+} ; \operatorname{TrkB}{ }^{f / / f l}$ mice with or without inducible Cre 247 expression in OPCs (referred to as Scn8a $a^{+/+}$and Scn8a ${ }^{+/+}$OPC cKO; Scn8a $a^{+/ m u t}$ and Scn8a 248 OPC cKO, respectively). All mice were treated with Tamoxifen (100 mg/kg IP) between post-natal 249 days 21-23 to ensure that any differences between genotype groups do not represent differences 250 in Tamoxifen treatment. Following Tamoxifen treatment, mice were implanted for 251 electrocorticography (EEG) to monitor seizure frequency in each group.

253 It should be noted that the original $\mathrm{Scn} 8 \mathrm{a}^{+/ m u t}$ mouse line is on a C3HeB/FeJ background, while 254 Scn8a ${ }^{+/ m u t} ; T_{r k B}^{f / f l}$ mice have a mixed C3HeB/FeJ and C57/BL6 background. Background strain 255 can influence the age and kinetics of seizure onset (Ferraro et al., 1999; Papandrea et al., 2009). 256 We therefore determined the timeline of epileptogenesis in Scn8a ${ }^{+/ m u t}$ mice with this mixed 257 background. In Scn8a ${ }^{+/ m u t}$ mice (mixed background) with intact activity-dependent myelination, 4$2588 \mathrm{~Hz}$ absence seizures begin around P45 (Figure 6A, C-D). Seizures then increase steadily and 259 occur 20-30 times per hour, on average, by 4-6 months of age (Figure 6A).

261 We next assessed whether deletion of the TrkB receptor from OPCs prevents the oligodendroglial 262 response to seizures. Consistent with prior studies (Geraghty et al., 2019), OPC-specific deletion 263 of TrkB does not alter homeostatic OPC numbers. Deletion of the TrkB receptor from OPCs in

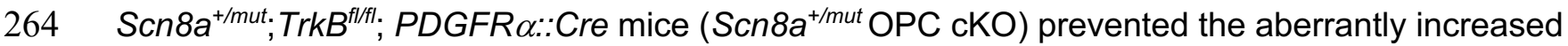
265 callosal OPC number found in $S c n 8 a^{+/ m u t}$ mice with intact activity-regulated myelin response, 266 (Figure 6B). 
268 Having elucidated the timeline of epileptogenesis and confirmed that TrkB deletion from OPCs

269 prevents OPC expansion in association with seizures, we next examined seizure frequency in $270 S c n 8 a^{+/ m u t}$ mice lacking TrkB expression in OPCs (Scn8a $a^{+/ m u t}$ OPC $\left.c K O\right)$. We found that seizure

271 burden was strikingly reduced in Scn8a ${ }^{+/ m u t}$ OPC cKO mice with impaired activity-dependent 272 myelination. Scn8a $a^{+/ m u t}$ mice with intact activity-regulated myelination exhibit a marked increase 273 in the number of seizures per hour over the period of epileptogenesis (Figure 6D-E). In contrast, 274 Scn8a $a^{+/ m u t}$ mice with OPC-specific loss of TrkB expression that lack activity-regulated myelination

275 (Figure 6B and Geraghty et al., 2019) exhibit substantially fewer seizures per hour, an effect that 276 was sustained at least until 6 months of age (Figure 6E). The mean duration of individual seizures

277 in Scn8a $a^{+/ m u t}$ mice was $2.3 \pm 0.2$ seconds, consistent with previously published findings in 278 Scn8a ${ }^{+/ m u t}$ mice (Makinson et al., 2017); the mean duration of individual seizures was not 279 significantly different in Scn8a $a^{+/ m u t}$ cKO mice (Supplemental Figure 4). Taken together, these 280 findings indicate that activity-dependent myelination contributes to kindling of absence seizures 281 during epileptogenesis.

\section{Discussion}

284 Childhood absence epilepsy, historically called "petit mal" seizures, is a common genetic 285 generalized epilepsy syndrome (Matricardi et al., 2014; Brigo et al., 2018). Although childhood 286 absence epilepsy has been considered relatively benign, this disease is associated with 287 considerable cognitive co-morbidity and poor psychosocial functioning (Verrotti et al., 2015; 288 Shinnar et al., 2017). Moreover, up to $35 \%$ of cases are refractory to medical therapy for unknown 289 reasons (Wirrell et al., 1996) and in 20 to $50 \%$ of patients, seizures return following medication 290 withdrawal (Matricardi et al., 2014). The natural history of the disease involves rapid, progressive 291 increases in seizure frequency and severity, similar to what is seen in animal models (Brigo et al., 292 2018). Recent evidence indicates that this period of seizure "kindling" is a key determinant of 293 disease severity in humans as well as rodent models, such that early blockade of absence 
294 seizures and/or their downstream effects mitigates morbidity (van Luijtelaar et al., 2013; Pitkanen 295 et al., 2015; Morse et al., 2019). It should also be noted that multiple (often medically intractable) 296 epilepsy syndromes involve typical and atypical absence seizures, at times in combination with 297 other seizures types, such as other generalized epilepsies and the often devastating epileptic 298 encephalopathy Lennox-Gastaut syndrome (Arzimanoglou et al., 2009; Pack, 2019). Thus, there 299 is an urgent need to understand mechanisms underlying epileptogenesis, which will be necessary 300 for disease-modifying and/or curative treatments for absence and other forms epilepsy.

302 Given recent appreciation that activity-regulated myelination can influence neural network 303 function (Pajevic et al., 2014; Noori et al., 2020; Steadman et al., 2020), we reasoned that 304 excessive and aberrant neuronal activity might abnormally increase myelination within seizure 305 networks in disorders such as absence epilepsy. Maladaptive myelination may, in turn, contribute 306 to disease pathogenesis, including seizure kindling. Further supporting the hypothesis that 307 increased myelination, particularly within corpus callosum, might contribute to seizure 308 susceptibility or severity, a rat strain with a propensity for provoked seizures exhibits increased 309 callosal myelination (Sharma et al., 2017). Here, in two distinct rodent models with spontaneous 310 absence seizures and well-defined periods of epileptogenesis, we found increased 311 oligodendrogenesis and myelination of the seizure network only after seizure onset. Increased 312 myelination did not occur when seizures were pharmacologically treated. We observed both an 313 increase in mean myelin sheath thickness as well as an increase in the number of myelinated 314 corpus callosum axons. Whether the change in myelinated axon number reflects de novo 315 myelination of previously unmyelinated axons or discontinuously myelinated axon segments 316 (Tomassy et al., 2014) remains to be determined. Furthermore, it is not yet clear whether the 317 increased sheath thickness reflects newly generated internodes or activity-regulated remodeling 318 by existing oligodendrocytes (Swire et al., 2019). Finally, the effects of seizure-associated 319 myelination on inhibitory interneurons (Zonouzi et al., 2019) and other neuronal subtypes remains 
320 to be explored in future studies. While these mechanistic questions remain to be elucidated, a

321 role for activity-regulated myelination in absence epileptogenesis is clear. Genetic blockade of

322 activity-dependent myelination during epileptogenesis reduced the frequency of daily seizures

323 over time. Together, our findings indicate that maladaptive, activity-regulated myelination

324 contributes to progressive increases (kindling) of absence seizures.

326 How might activity-regulated myelination become maladaptive, contributing to further disease

327 progression? In general, epileptogenesis in absence and other forms of epilepsy is thought to

328 reflect increased neuronal excitation and synchrony of neuronal firing (McCormick and Contreras,

329 2001; Jefferys et al., 2012; Pitkanen et al., 2015; Fogerson and Huguenard, 2016). Activity-

330 regulated myelination promotes oscillatory synchrony (Pajevic et al., 2014; Noori et al., 2020;

331 Steadman et al., 2020); thus, aberrantly increased activity-regulated myelination may contribute

332 to thalamocortical hypersynchrony underlying absence epilepsy. Consistent with our observations

333 of increased callosal myelination, abnormally increased interhemispheric synchrony between the

334 somatosensory cortices is well demonstrated in absence epilepsy (Mishra et al., 2013).

335 Additionally, changes in myelination and consequent alterations to temporal dynamics within the

336 seizure network could influence spike timing-dependent synaptic plasticity (Bi and Poo, 2001) and

337 thus affect neuronal excitation. Increased myelination might also serve as a compensatory

338 mechanism that provides metabolic support and enables rapid firing during seizures (Nave, 2010;

339 Funfschilling et al., 2012). Finally, oligodendroglial cells can influence neuronal excitability.

340 Satellite oligodendrocytes are electrically coupled with astrocytes via gap junctions in a

341 "syncytium" which buffers potassium to constrain neuronal excitability (Battefeld et al., 2016).

342 Similarly, conditional deletion of the inward rectifying potassium channel Kir4.1 from

343 oligodendrocytes impairs potassium clearance, leading to hyperexcitability and decreased

344 seizure threshold (Larson et al., 2018). A subset of CNS oligodendrocytes express glutamine

345 synthetase and directly modulate glutamatergic excitatory neurotransmission (Xin et al., 2019). In 
absence epilepsy, the impact of the observed increase in oligodendrogenesis and myelination upon potassium buffering and potassium-related neuronal excitability remains to be determined. Future work will investigate network level mechanisms by which myelin plasticity contributes to kindling, which may include promoting the thalamocortical and interhemispheric hyper-synchrony characteristic of absence epilepsy (Huntsman et al., 1999; Makinson et al., 2017).

352 Our finding that seizures are markedly reduced but not entirely prevented by blockade of activity-

353 dependent myelination suggests that multiple mechanisms are responsible for progressive 354 increases in daily seizure burden observed in Scn8a mice. This is consistent with previous 355 findings that Scn8a loss of function, presumably unaffected by genetic blockade of activityregulated oligodendrogenesis, leads to thalamocortical hypersynchrony and seizures due to interneuron dysfunction in the reticular thalamic nucleus (Makinson et al., 2017). Altered function of voltage-gated calcium channels (Pietrobon, 2002), GABA receptors (Seo and Leitch, 2014), hyperpolarization-activated cyclic nucleotide-gated potassium channels (Ludwig et al., 2003), and glucose transport (Marin-Valencia et al., 2012) also cause or contribute to absence

361 epileptogenesis. Extensive studies have elucidated altered neuronal physiology in the 362 thalamocortical network leading to absence seizures (von Krosigk et al., 1993; Steriade and 363 Contreras, 1998; Huntsman et al., 1999; Paz et al., 2011), while the involvement of glial cells in 364 the pathogenesis of absence epilepsy is only beginning to be recognized. The early studies of 365 glia in epilepsy pathogenesis have focused chiefly on astrocytes (Coulter and Steinhauser, 2015). 366 Impaired GABA transport in astrocytes was found to promote tonic, rather than phasic, GABA-A 367 signaling, potentiating absence seizures in multiple models of absence epilepsy (Cope et al., 368 2009); astrocyte-mediated glutamate metabolism also regulates the duration of thalamocortical 369 epileptiform oscillations (Bryant et al., 2009); endozepine modulation of GABA-A currents in the 370 reticular thalamic nucleus, a significant determinant of seizure severity, was also found to be 371 regulated by astrocytes (Christian et al., 2013; Christian and Huguenard, 2013). Increased GFAP 
expression has been noted throughout the thalamocortical network in absence epilepsy, further supporting the idea of astrocyte dysregulation or reactivity (Cavdar et al., 2019). More broadly, in multiple forms of epilepsy, an array of astrocyte-mediated mechanisms - including impaired glutamate and excitatory amino acid metabolism, potassium buffering, gap junction and aquaporin expression - are thought to contribute to hyperexcitability and seizures (Eid et al., 2019). Further, neuro-inflammation involving microglia, astrocytes and brain vasculature significantly modulates disease severity in some forms of epilepsy, reviewed in (Vezzani et al., 2019). In addition to these

379 findings demonstrating effects of glia on neuronal hyperexcitability in multiple forms of epilepsy, here we hypothesize a role for oligodendrocytes in modulating neural network synchrony.

Given the diverse array of mechanisms occurring in different forms of epilepsy, it is likely that the

392 mesial temporal lobe epilepsy (Vezzani et al., 2011), might be associated with diminished white 393 matter plasticity due to effects of reactive microglia on oligodendroglial cells (Miron et al., 2013;

394 Gibson et al., 2019). Underscoring the likely heterogeneity of myelin changes in different seizure 395 types, brief acute generalized tonic-clonic seizures did not induce an oligodendroglial response 396 in a previous study (Gibson et al., 2014). Thus, future work should investigate the likely 397 heterogeneous patterns and functional roles of myelination in diverse forms of epilepsy. 
399 The findings presented here highlight avenues for potential therapeutic interventions targeting 400 aberrantly increased oligodendrogenesis and myelination. In the case of absence seizures, we

401 found that genetic blockade of activity-dependent myelination by targeted removal of TrkB from 402 OPCs (Geraghty et al., 2019) reduced seizure burden. Therapeutically targeting BDNF signaling, 403 a pathway critical to many adaptive processes (Kowianski et al., 2018) may confer risks to 404 cognition and neurodevelopment that outweigh the benefit to seizure severity. Alternatively, 405 oligodendrogenesis can be targeted using pharmacological histone deacetylase (HDAC) 406 inhibitors to epigenetically interrupt oligodendroglial differentiation (Wu et al., 2012; Gibson et al., 407 2014). Indeed, HDAC inhibition has been shown to improve the course of absence epilepsy in 408 Wag/Rij rats (Citraro et al., 2020), although the link to myelination has not been previously 409 appreciated. Such strategies targeting aberrant oligodendrogenesis may prove particularly helpful 410 in refractory cases of childhood absence epilepsy, and/or in preventing oligodendrogenesis in 411 epilepsy syndromes defined by intractable forms of absence seizures, such as Lennox-Gastaut 412 syndrome (Camfield, 2011). More broadly, the finding that aberrant activity-regulated myelination 413 can contribute to seizure kindling suggests that maladaptive myelination may be a therapeutically 414 targetable pathogenic mechanism in neurological and neuropsychiatric diseases defined by 415 recurrent patterns of abnormal neuronal activity.

417 Author Contributions J.K.K. performed experiments and analyzed quantitative microscopy and 418 electrophysiological data. C.S., E.F., L.T.T., D.F., A.B., T.S. and H.X. performed experiments and 419 assisted with data analysis. L.T.T., A.B. and K.V. assisted with animal husbandry and drug 420 administration. L.N. performed electron microscopy. J.K.K., M.M. and J.H. conceived of the 421 project. J.K.K., M.M. wrote the manuscript. H.X., A.B., and E.F. C.S., E.F., L.T.T., D.F., A.B., T.S. 422 and H.X. edited the manuscript. M.M. and J.H. supervised all aspects of the work. 
424 Acknowledgements: The authors gratefully acknowledge support from the National Institute of

425 Neurological Disorders and Stroke (R01NS092597 to M.M, K12NS098482-02 to J.K.K., 426 R01NS034774 to J.H.), NIH Director's Pioneer Award (DP1NS111132 to M.M.), Kleberg

427 Foundation, Stanford Maternal and Child Health Research Institute (to M.M. and J.K.K.), Bio-X

428 Institute (to M.M. and J.K.K.), Cancer Research UK (to M.M.), American Epilepsy Society and 429 CURE Epilepsy Foundation (to J.K.K.). The authors wish to thank Michelle Fogerson, Jordan 430 Sorokin, Austin Reese and Christopher Makinson for their guidance on performing and analyzing 431 rodent EEG. The authors also thank Dr. Steve Chinn at Stanford Children's Health for his 432 assistance with ethosuximide experiments.

434 Declaration of Interests: The authors declare no competing interests 
Figure 1: Oligodendrogenesis increases within the absence seizure network after seizure onset in Wag/Rij rats.

A

B

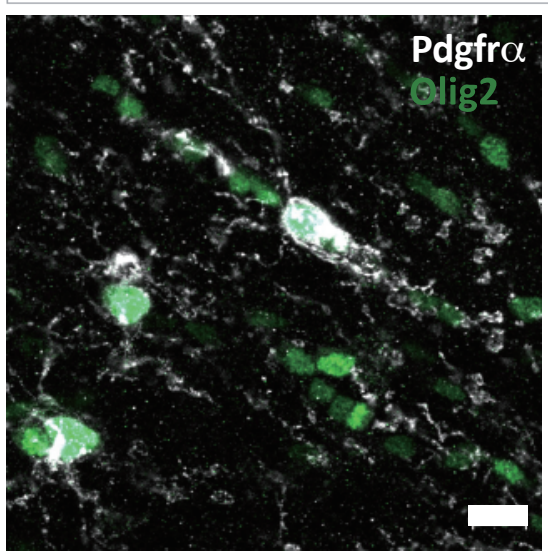

C

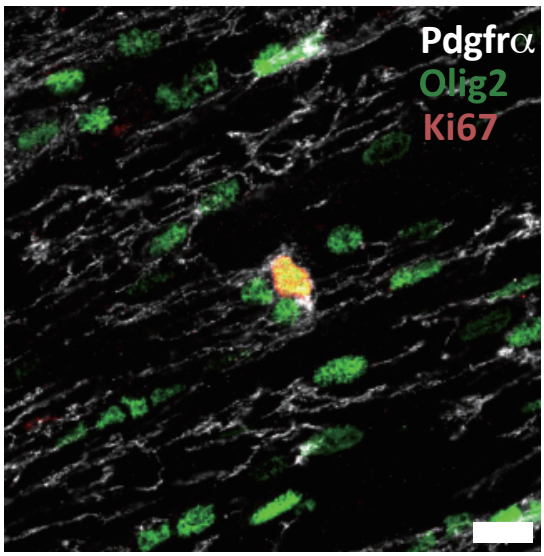

D

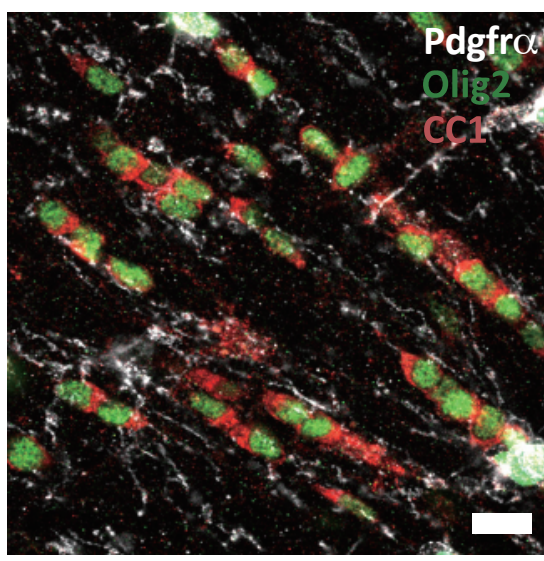

a)

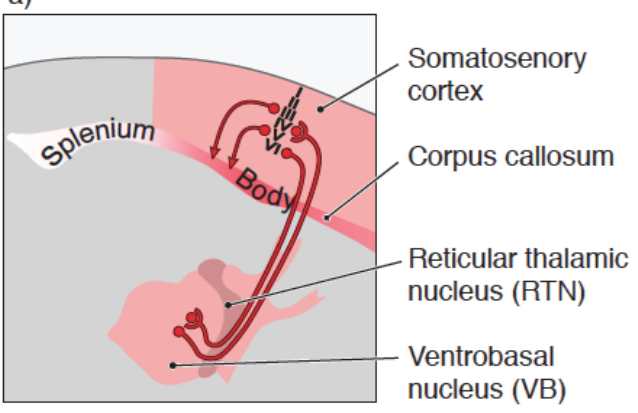

b)

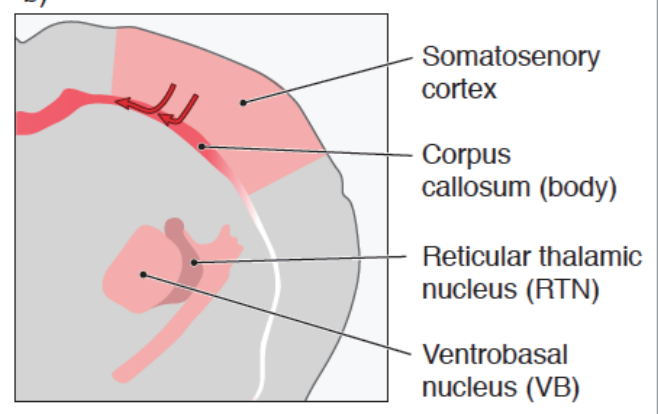

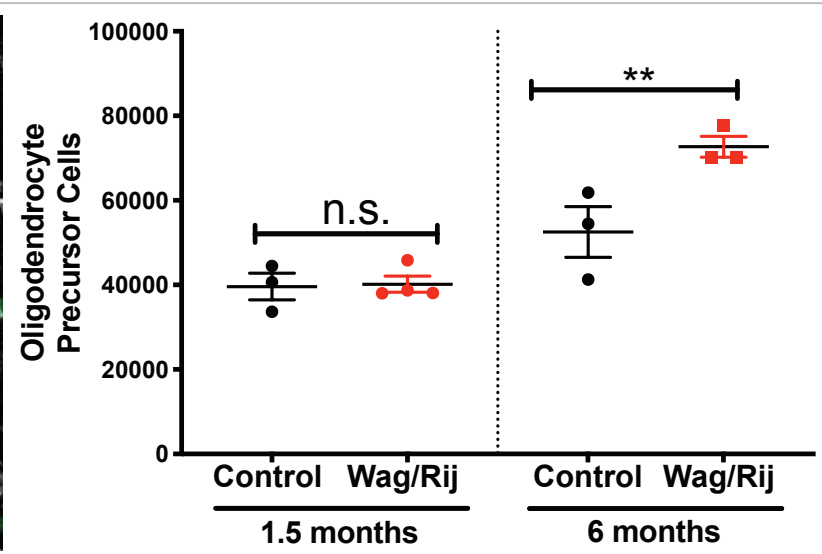
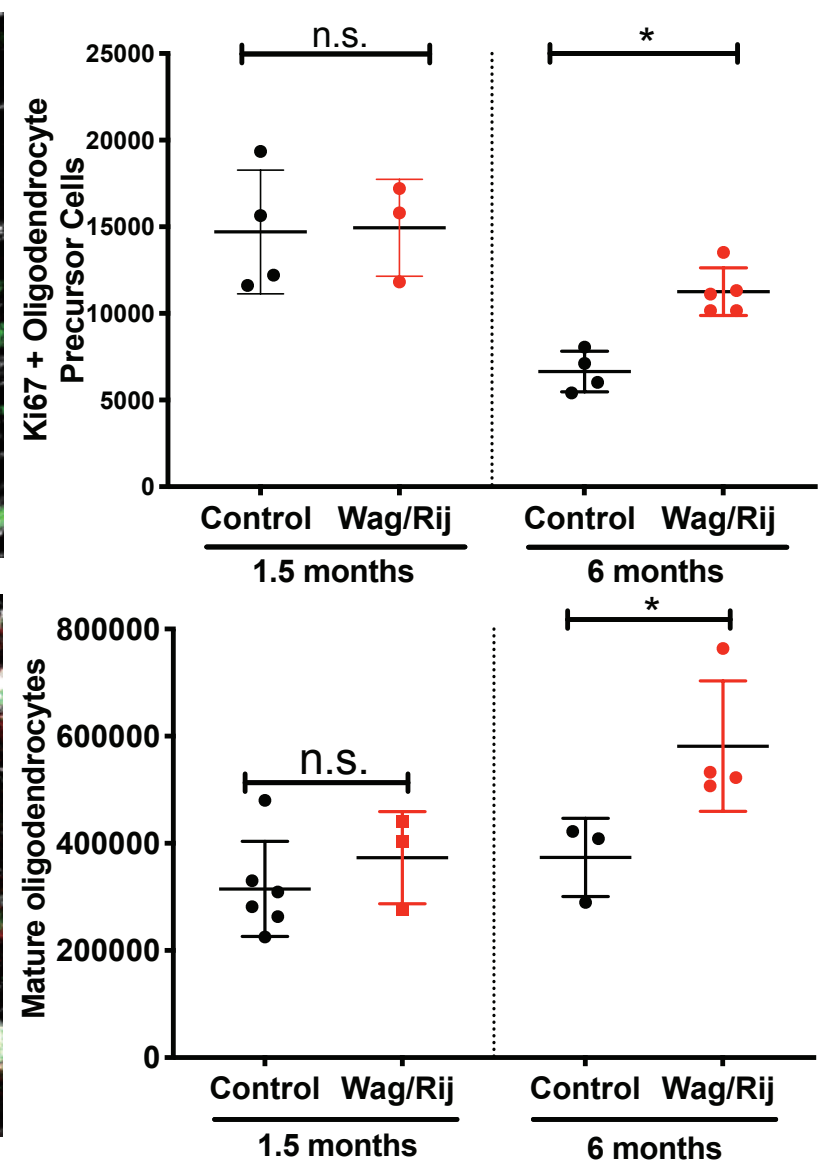
436 Figure 1: Oligodendrogenesis increases within the absence seizure network after seizure

437 onset in Wag/Rij rats.

438 (A) Schematic of absence seizure network illustrating propagation through the body of the

439 corpus callosum. Schematic demonstrates sagittal (a) and coronal (b) views of the absence

440 seizure network, shown in pink/red. Absence seizures result from hypersynchronous oscillations

441 between the thalamus and cortex; in rodents, seizure activity is particularly prominent in

442 connections between the ventrobasal and reticular thalamic nuclei and somatosensory cortices.

443 Seizure activity propagates across the body of the corpus callosum, leading to bi-hemispheric

444 generalization. In humans, absence seizures are frontally predominant and in rodents, there is

445 little involvement of the occipital cortices and posterior region of the corpus callosum (splenium)

446 that connects them.

447 (B) Absence epileptogenesis is associated with increased callosal oligodendrocyte

448 precursor cells. Left: representative photomicrograph of callosal oligodendrocyte progenitor

449 cells (OPCs) from a 6-month old control rat co-expressing Olig2 (green) and PDGFR $\alpha$ (white);

450 scale bar, $10 \mu \mathrm{m}$. Other oligodendroglial lineage cells express Olig2 (green only) but not

451 PDGFR $\alpha$. Right: Unbiased stereological quantification of oligodendrocyte precursor cells (OPCs)

452 in the body of the corpus callosum at 1.5 months of age (prior to seizure onset) and 6 months of 453 age (after seizures are well-established in Wag/Rij rats) in control (Wistar) and Wag/Rij rats. Black

454 dots represent control rats and red dots represent Wag/Rij rats. Each data point represents total

455 OPC number from 1 rat; 477-909 cells were counted per rat (1.5-month timepoint) and 735-1154

456 cells were counted per rat at the 6-month timepoint. Data represent mean \pm SEM. 1.5 -month

457 timepoint, $\mathrm{n}=3$ control, 4 Wag/Rij rats; 6-month timepoint, $\mathrm{n}=3$ control, 3 Wag/Rij rats.

458 (C) Absence epileptogenesis is associated with increased callosal OPC proliferation. Left:

459 representative photomicrograph of a dividing OPC from a 6-month-old control rat co-expressing 460 Olig2 (green), PDGFR $\alpha$ (white) and Ki67 (red). Scale bar is $10 \mu \mathrm{m}$. Right: Unbiased stereological 
461 quantification of proliferating oligodendrocyte precursor cells (OPCs) in the body of the corpus

462 callosum at 1.5 months of age (prior to seizure onset) and 6 months of age (after seizures are

463 well-established in Wag/Rij rats) in control (Wistar) and Wag/Rij rats. Each data point represents

464 total Ki67-OPC number for one rat. At the 1.5-month timepoint, 426-734 cells were counted per

465 rat, while 229-448 cells were counted per rat at the 6-month timepoint (1.5-month timepoint, $\mathrm{n}=$

4664 control, 3 Wag/Rij; 6-month timepoint, $n=4$ control, 5 Wag/Rij rats).

467 (D) Absence epileptogenesis is associated with increased callosal oligodendrocytes. Left:

468 representative photomicrograph of mature oligodendrocytes in the corpus callosum of a 6-month

469 old control rat, co-expressing Olig2 (green) and CC1 (red). These cells are distinct from precursor

470 cells, which express PDGFR $\alpha$ (white) and Olig2. Scale bar is $10 \mu \mathrm{m}$. Right: Unbiased

471 stereological quantification of mature oligodendrocytes in the body of the corpus callosum at 1.5

472 months of age (prior to seizure onset) and 6 months of age (after seizures are well-established in

473 Wag/Rij rats) in control (Wistar) and Wag/Rij rats. Each data point represents total mature

474 oligodendrocytes for 1 rat; at the 1.5-month timepoint, 478-1102 cells were counted for each rat

475 while at the 6-month timepoint, 757-1522 cells were counted for each rat. (1.5-month timepoint,

$476 \mathrm{n}=6$ control, 3 Wag/Rij; 6-month timepoint, $n=3$ control, 4 Wag/Rij rats).

478 For all panels in this figure, data were analyzed by ANOVA with post-hoc Sidak's test (comparing

479 groups within 1.5 month or 6-month timepoints), correcting for multiple comparisons. For all

480 panels, ${ }^{*} p<0.05,{ }^{* *} p<0.01,{ }^{* *} p<0.001$, n.s. $=p>0.05$ 
Figure 2: Myelination increases within the absence seizure network in Wag/Rij rats.

A

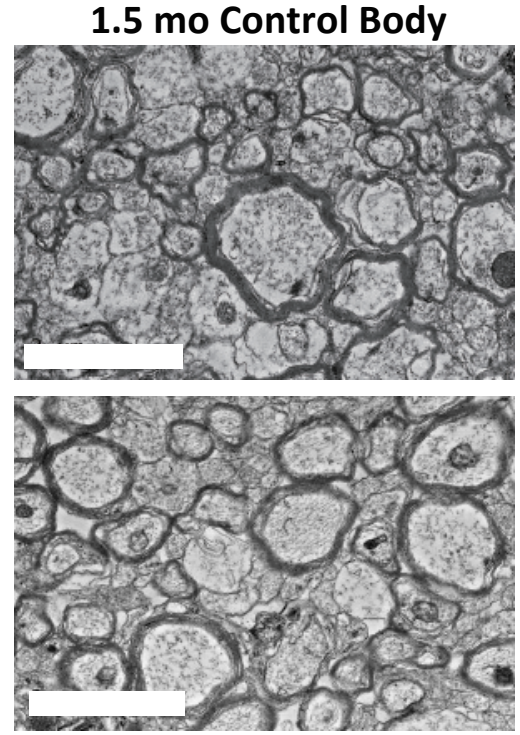

1.5 mo Wag/Rij Body

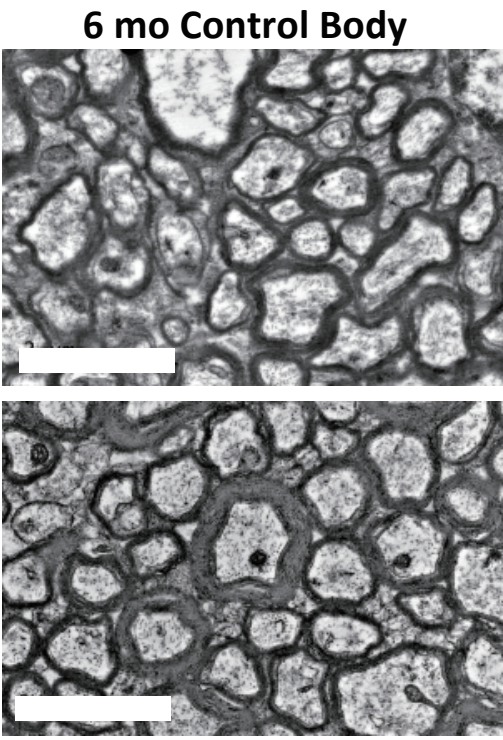

6 mo Wag/Rij Body
B

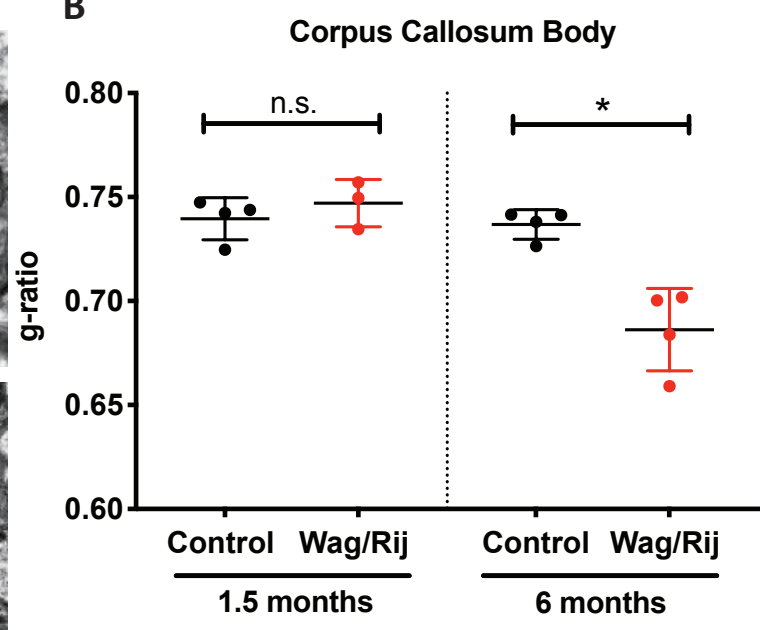

Corpus Callosum Body

C Corpus Callosum Body

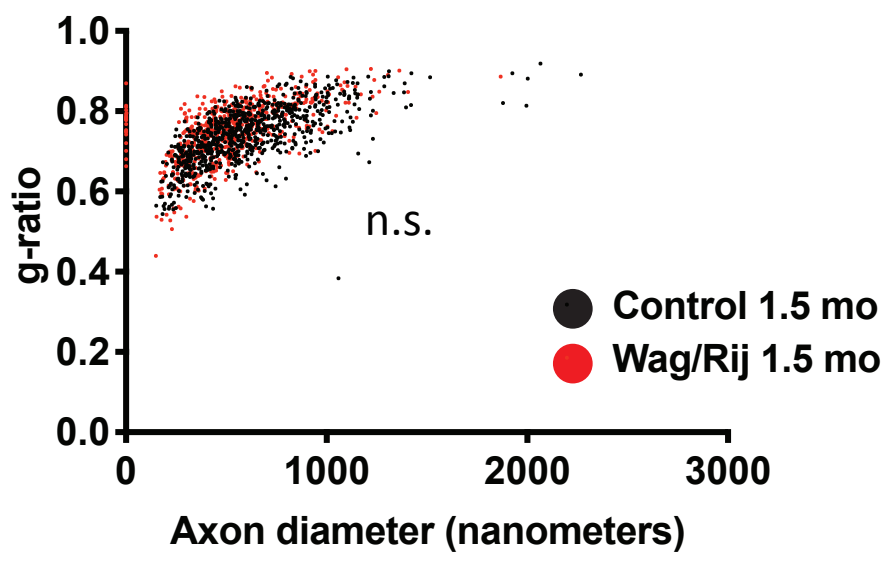

E

$\mathbf{F}$

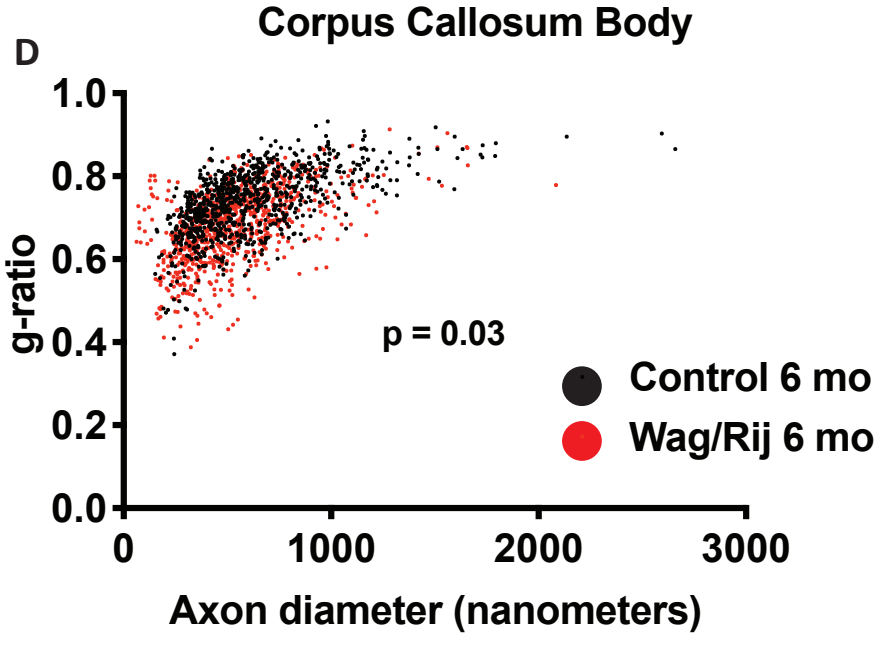

G

Corpus Callosum Splenium
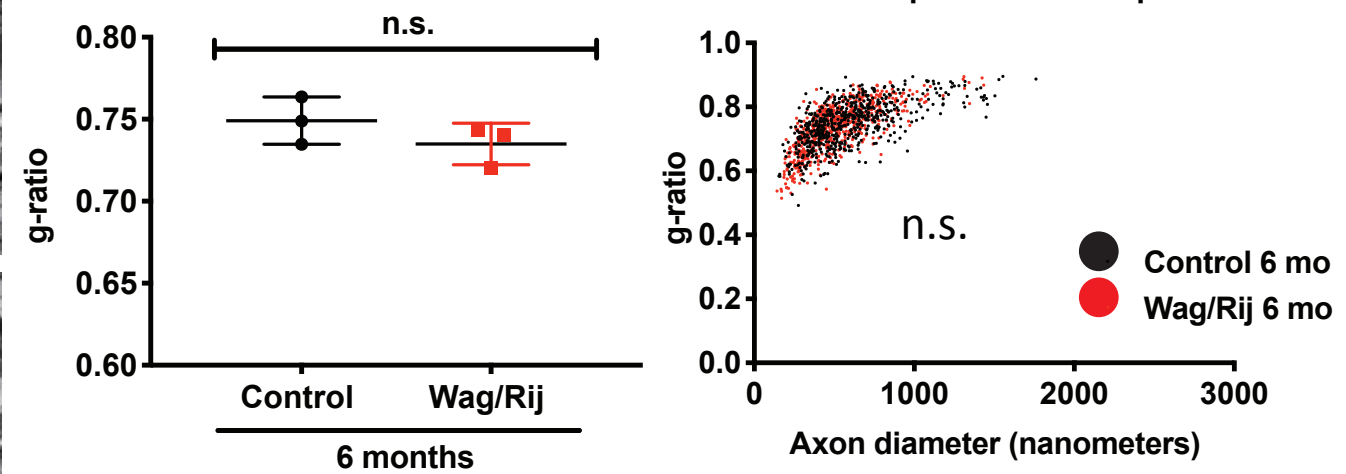

$6 \mathrm{mo} \mathrm{Wag/Rij} \mathrm{Splenium}$ 
483 Figure 2: Myelination increases within the absence seizure network in Wag/Rij rats.

484 (A) Myelin sheaths appear thicker in Wag/Rij rats with seizures. Representative transmission

485 electron microscopy images of myelinated axon cross sections in the mid-sagittal body of the

486 corpus callosum of 1.5-month (left) and 6-month-old (right) control rats (upper panels) and

487 Wag/Rij rats (lower panels). Scale bar $=2$ micrometers.

488 (B-D) Quantitative analysis indicates increased myelin sheath thickness in Wag/Rij rats

489 after epileptogenesis. (B) Mean g-ratio (axon diameter divided by the diameter of the entire 490 fiber) of axons in the body of the corpus callosum in 1.5-month old and 6-month old Wag/Rij rats

491 (red dots) and age-matched control rats (black dots). Smaller $g$-ratio values indicate thicker myelin

492 sheaths. Each dot represents the mean g-ratio for one rat. For each rat, 195-264 axons were 493 measured from 8-17 electron micrographs. Data represent mean \pm SEM and were analyzed by 494 ANOVA with post-hoc Sidak's testing. 1.5-month timepoint, $n=4$ control, 3 Wag/Rij rats; 6-month 495 timepoint, $\mathrm{n}=4$ control, 4 Wag/Rij rats. (C-D) Scatterplots of individual axon g-ratio 496 measurements which were shown as means in (B), from 1.5-month-old rats (C) and 6-month-old 497 rats (D), as a function of axon diameter. Each data point represents one axon, with control axons 498 in black and Wag/Rij axons in red. 1.5-month time-point: $n=4$ control, 3 Wag/Rij rats; 6-month 499 time-point: $\mathrm{n}=4$ control, 4 Wag/Rij rats.

500 (E-G) Increased myelination is specific to the seizure network. (E) Representative 501 transmission electron micrographs of myelinated axons in the splenium of a 6-month-old control 502 rat (upper panel) and a Wag/Rij rat (lower panel). Scale bar $=2 \mu \mathrm{m}$. (F) Mean $g$-ratio of axons in 503 the splenium of the corpus callosum in 6-month old Wag/Rij rats (red dots) and age-matched 504 control rats (black dots). For each rat, 197-217 axons from 10-14 fields were quantified. $\mathrm{n}=3$ 505 control, $3 \mathrm{Wag} / \mathrm{Rij}$ rats. Data represent mean \pm SEM and were analyzed with a t-test. (G) 506 Scatterplot of individual axon g-ratio measurements shown as means in (F). Each data point 507 represents one axon, with control axons in black and Wag/Rij axons in red. $n=3$ control, 3 508 Wag/Rij rats. 
bioRxiv preprint doi: https://doi.org/10.1101/2020.08.20.260083; this version posted August 21, 2020. The copyright holder for this preprint (which was not certified by peer review) is the author/funder. All rights reserved. No reuse allowed without permission.

509 For all panels in this figure, ${ }^{*} p<0.05,{ }^{* *} p<0.01,{ }^{* *} p<0.001$, n.s. $=p>0.05$

510 
Figure 3: Seizures are necessary for aberrant callosal myelination.

A

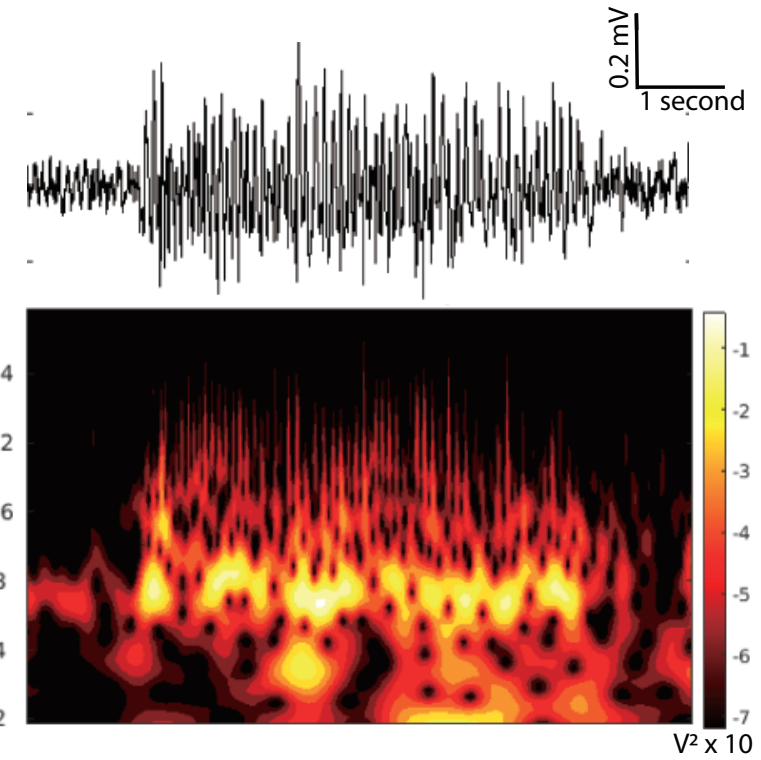

C
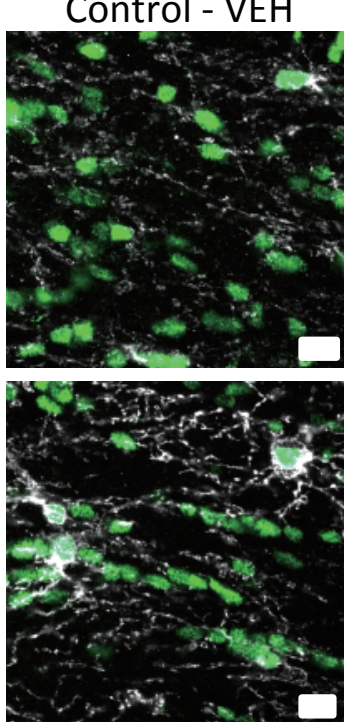

Wag/Rij - VEH
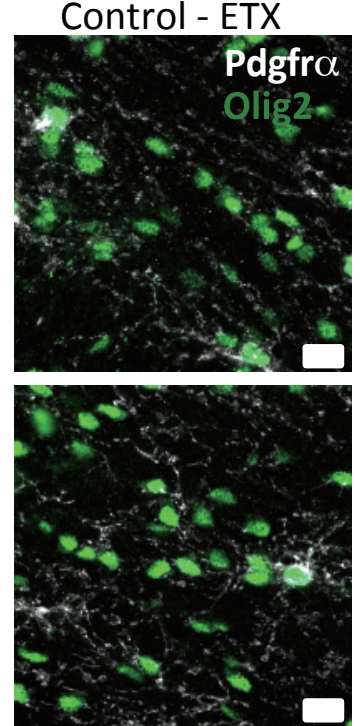

Wag/Rij - ETX

E

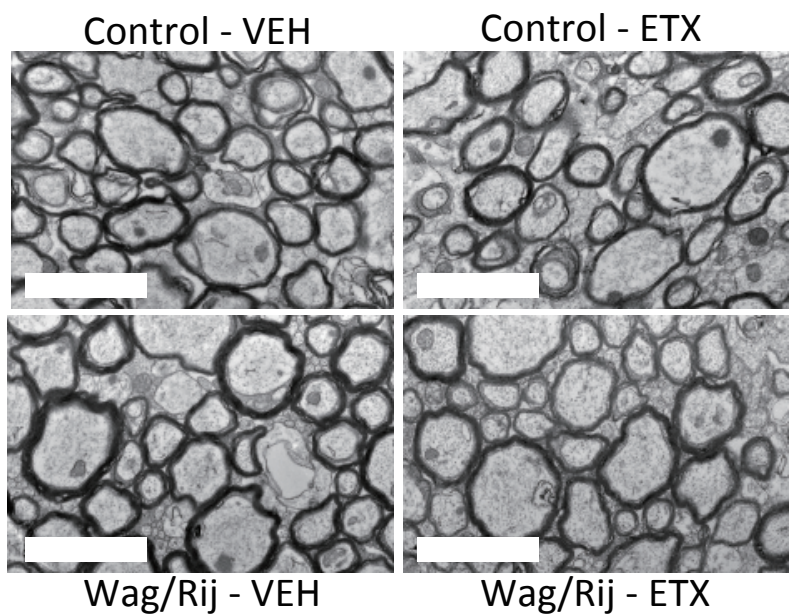

B
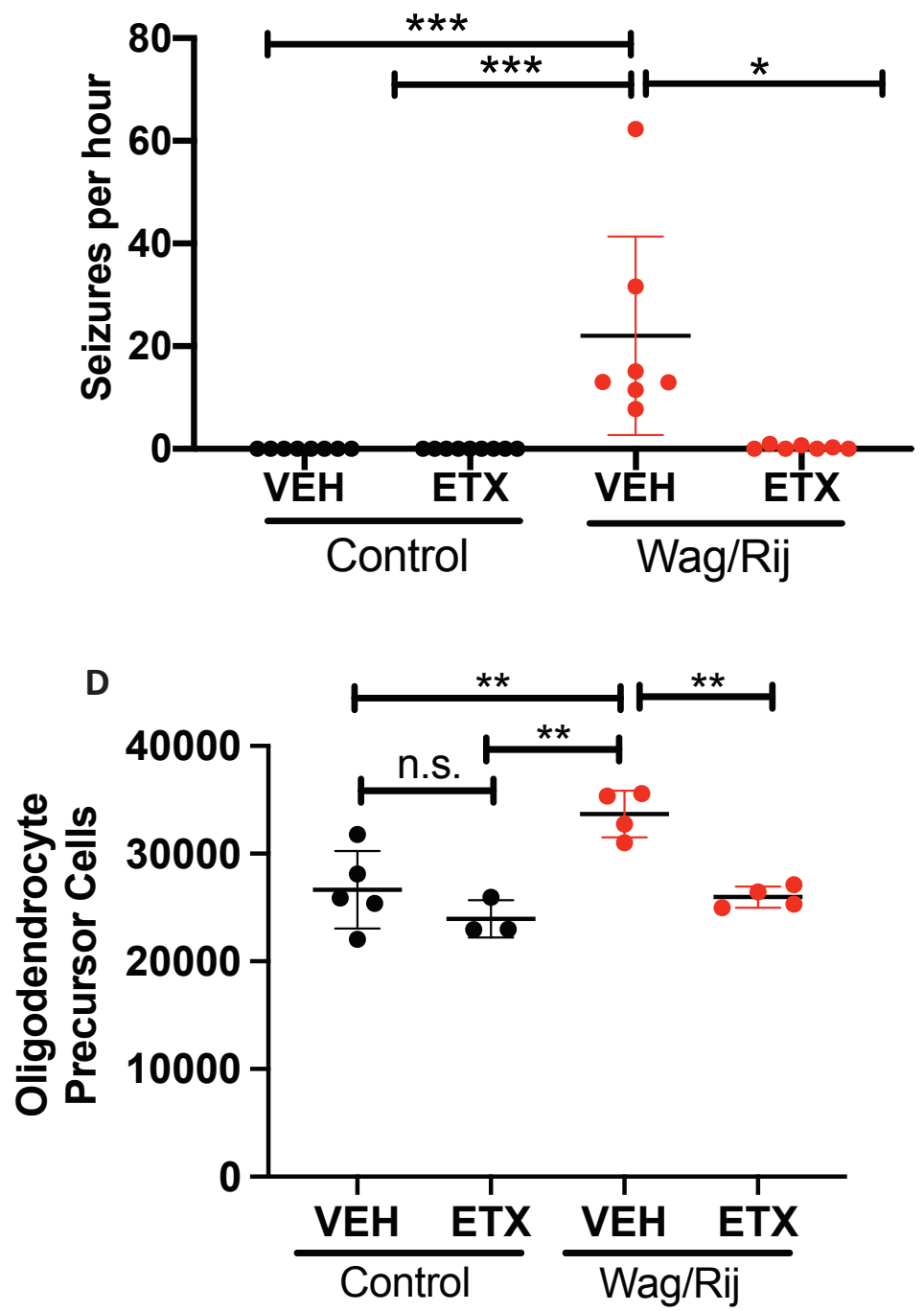

F

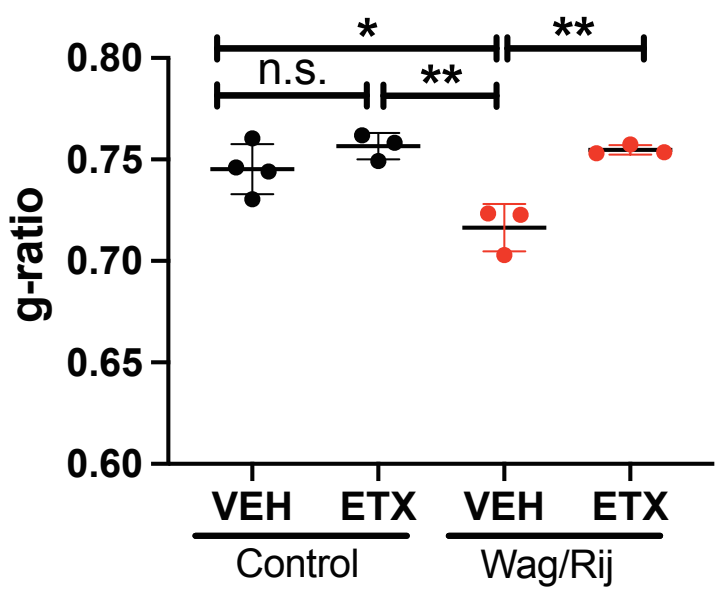


511 Figure 3: Seizures are necessary for aberrant callosal myelination. Control and Wag/Rij rats

512 were treated with vehicle (VEH) or ethosuximide (ETX) during the period of epileptogenesis, from

5131.5 months to 7 months of age. Electroencephalograms (EEGs) were recorded at 6.5 months of 514 age.

515 (A) Representative spike-wave discharge seizure from a 6.5-month-old vehicle-treated Wag/Rij

516 rat (upper panel); spectral analysis demonstrating the predominant seizure frequency is $8 \mathrm{~Hz}$ 517 (lower panel).

518 (B) Ethosuximide (ETX) decreases seizures in Wag/Rij rats. Quantitative analysis of EEG 519 recordings demonstrated well-established seizures in 6.5-month old vehicle (VEH)-treated 520 Wag/Rij rats $(22.0 \pm 7.3$ seizures per hour $)$, whereas seizures were significantly decreased or 521 absent in Wag/Rij rats treated with ETX (0.55 \pm 0.31 seizures/hour). Each data point represents 522 the mean seizures per hour for one rat; Control-VEH, $n=8$ rats; Control-ETX, $n=9$ rats; Wag/Rij$523 \mathrm{VEH}, \mathrm{n}=7$ rats; Wag/Rij-ETX, $\mathrm{n}=7$ rats. Data represent mean \pm SEM and were analyzed by the 524 Kruskal-Wallis and Dunn's multiple comparisons tests.

525 (C-D) ETX treatment normalizes OPC number in Wag/Rij rats. (C) Representative 526 photomicrographs demonstrating increased OPCs (co-expressing PDGFR $\alpha$, white and Olig2, 527 green) in the body of the corpus callosum of 7-month old VEH-treated Wag/Rij rats compared to 528 age-matched control rats treated with vehicle (VEH) or ETX and Wag/Rij rats treated with ETX.

529 Scale bar $=10 \mu \mathrm{m}$. (D) Unbiased stereological quantification of OPCs in the body of the corpus 530 callosum at 7 months of age in VEH or ETX-treated Wag/Rij or control rats. Each data point 531 represents the OPC number for one rat; 474-926 cells were counted per rat. Note one half of the 532 brain was used for these analyses and accordingly total OPC number measurements were $\sim 50 \%$ 533 of those in Figure 1B, which utilized both sides of the brain. Control-VEH, $n=5$ rats; Control-ETX, $534 \mathrm{n}=3$ rats; Wag/Rij-VEH, $\mathrm{n}=4$ rats; Wag/Rij-ETX, $\mathrm{n}=4$ rats. Data represent mean $\pm \mathrm{SEM}$ and 535 were analyzed by ANOVA with Tukey-Kramer post-hoc testing. 
536 (E-F) ETX treatment normalizes myelination in Wag/Rij rats. (E) Representative transmission

537 electron micrographs demonstrating increased myelin sheath thickness in some axons in the body

538 of the corpus callosum of 7-month old VEH-treated Wag/Rij rats compared to age-matched control

539 rats treated with VEH or ETX and Wag/Rij rats treated with ETX. Scale bar $=2 \mu \mathrm{m}$. (F) Mean g-

540 ratio of axons in the body of the corpus callosum in 7-month-old Wag/Rij (red dots) and control

541 rats (black dots) treated with VEH or ETX, as determined by transmission electron microscopy.

542 Each data point represents the mean g-ratio from 1 rat; 184-284 axons from 8-15 fields were

543 quantified for each rat. Control-VEH, $n=4$ rats; Control-ETX, $n=3$ rats; Wag/Rij-VEH, $n=3$ rats;

544 Wag/Rij-ETX, $n=3$ rats. Data represent mean \pm SEM and were analyzed by ANOVA with Tukey-

$545 \quad$ Kramer post-hoc testing.

546

547 For all panels in this figure, ${ }^{*} p<0.05,{ }^{* *} p<0.01,{ }^{* * *} p<0.001$, n.s. $=P>0.05$. 
Figure 4: Increased oligodendrogenesis within the seizure network after seizure onset in Scn8at/mut mice.

A

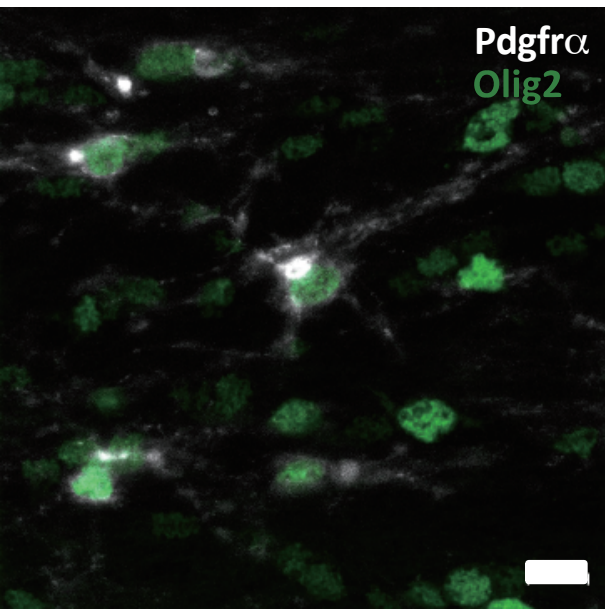

C

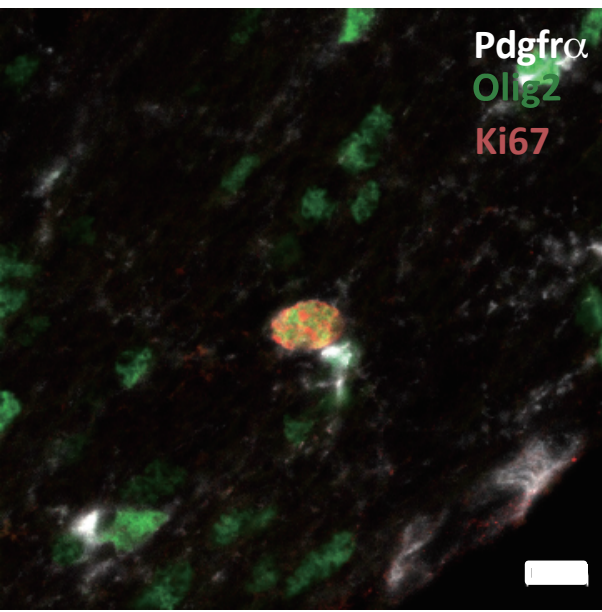

$E$

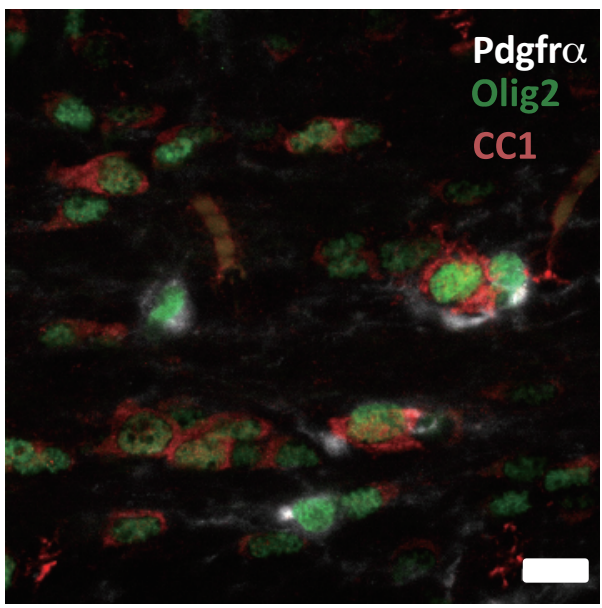

Bu

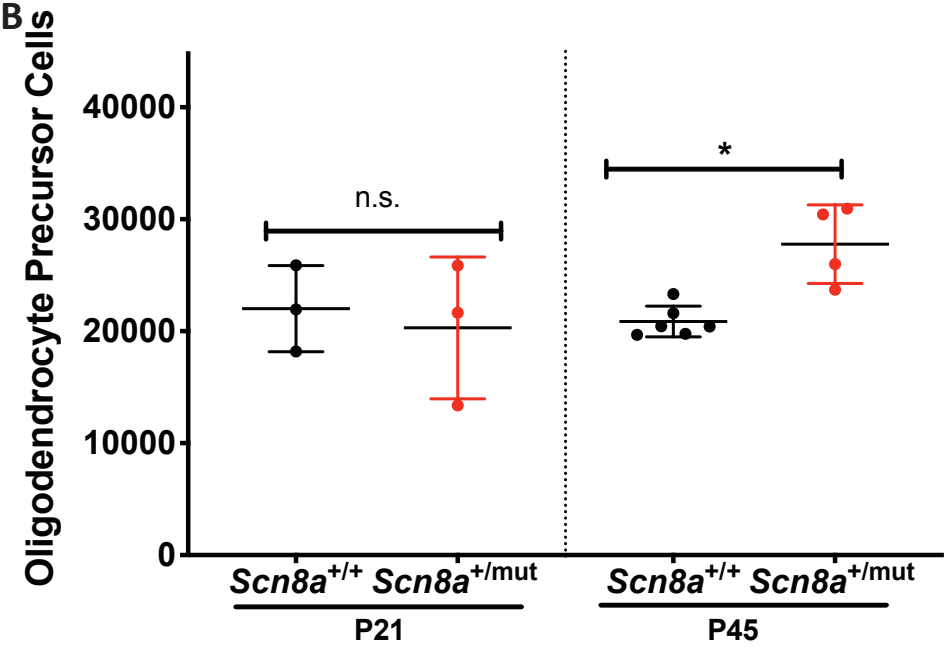

D

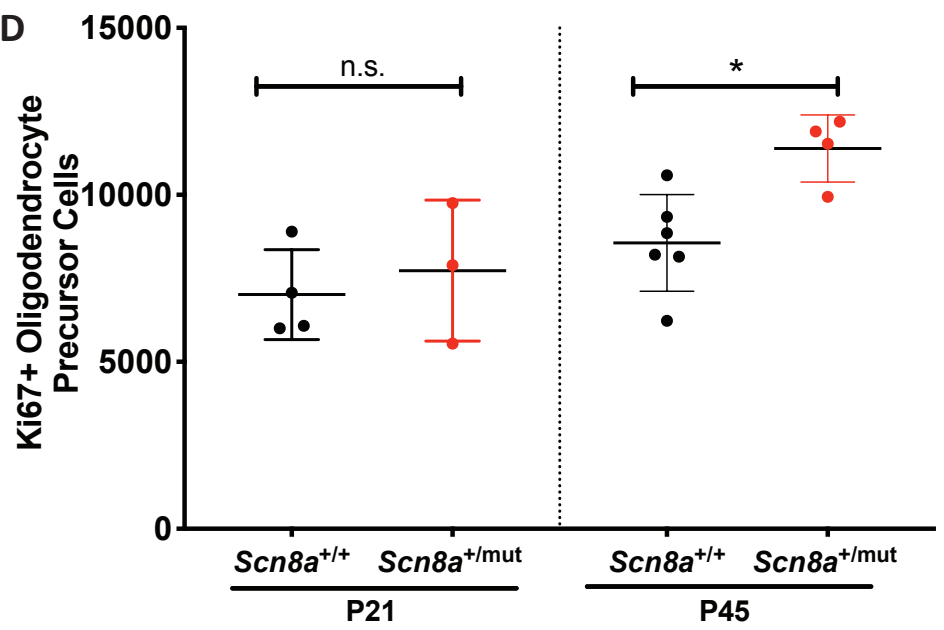

$\mathbf{F}$

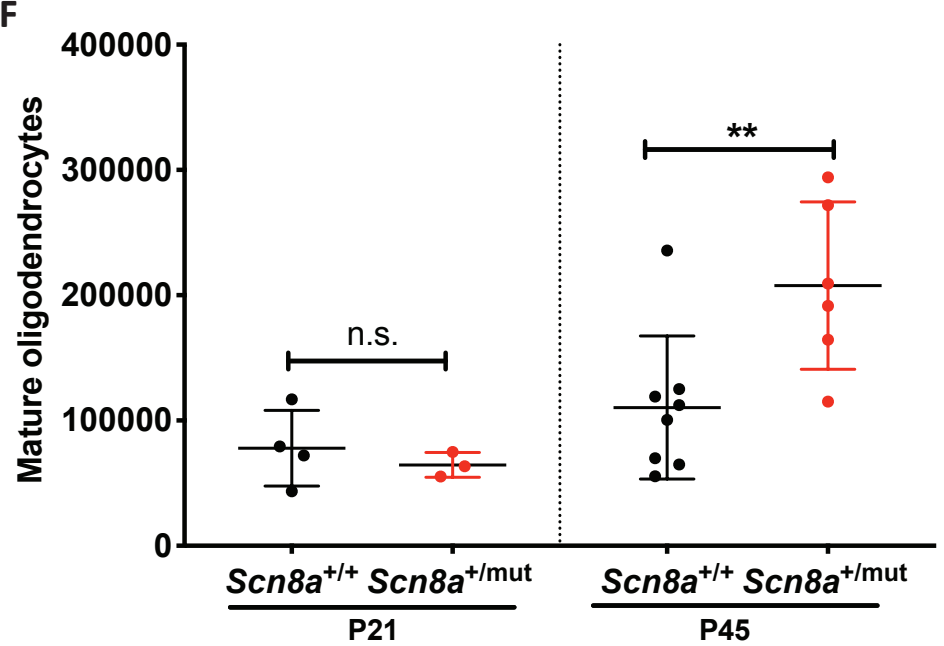


Figure 4: Increased oligodendrogenesis within the seizure network after seizure onset in Scn $8 a^{+/ m u t}$ mice.

551 (A-B) Absence epileptogenesis in Scn8a $a^{+/ m u t}$ mice is associated with increased callosal

552 OPC number. (A) Representative photomicrograph of OPCs co-expressing PDGFR $\alpha$ (white) and 553 Olig2 (green) from a Scn8a ${ }^{+/+}$mouse. Other oligodendroglial lineage cells which are not OPCs express Olig2 but not PDGFR $\alpha$. Scale bar $=10 \mu \mathrm{m}$. (B) Unbiased stereological quantification of OPCs in the body of the corpus callosum at 21 post-natal days (P21) (prior to seizure onset) and P45 (after seizures are well-established in Scn8a ${ }^{+/ m u t}$ mice). (P21, Scn8a $a^{+/+} n=3$ mice; Scn8a $8 a^{+/ m u t}$

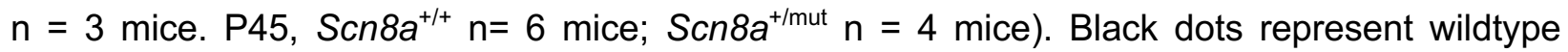

558 littermates $\left(S c n 8 a^{+/+}\right)$while red dots represent Scn8a $a^{+/ m u t}$ mice. Data represent mean \pm SEM; each 559 dot represents one animal. For each mouse, 348-672 cells (P21 mice) or 271-535 cells (P45 mice) 560 were counted.

561 (C-D) Absence epileptogenesis in Scn8a ${ }^{+/ m u t}$ mice is associated with increased OPC

562 proliferation. (C) Representative photomicrograph of dividing callosal OPC co-expressing Ki67

563 (red), PDGFR $\alpha$ (white) and Olig2 (green) from a Scn8a ${ }^{+/+}$mouse. Scale bar $=10 \mu \mathrm{m}$. (D)

564 Unbiased stereological quantification of proliferating OPCs in the body of the corpus callosum at

565 P21 and P45 in Scn8a ${ }^{+/ m u t}$ (red dots) and Scn8a ${ }^{+/+}$mice (black dots). Data represent mean \pm 566 SEM; each dot represents the number of proliferating OPCs for one animal. For each P21 mouse, 567 220-316 Ki67+ OPCs were counted; for each P45 mouse, 174-347 Ki67+ OPCs were counted. $568\left(P 21\right.$, Scn8a $a^{+/+} n=4$ mice; Scn8a $a^{+/ m u t} n=3$ mice. P45, Scn8a $a^{+/+} n=6$ mice; Scn8a $a^{+/ m u t} n=4$ mice).

569 (E-F) Absence epileptogenesis in Scn8a ${ }^{+/ m u t}$ mice is associated with increased 570 oligodendrogenesis. (E) Representative photomicrograph of callosal mature oligodendrocyte 571 expressing CC1 (red) and Olig2 (green), but not PDGFR $\alpha$ (white) from a Scn8a ${ }^{+/+}$mouse. Scale

572 bar $=10 \mu \mathrm{m}$. (F) Unbiased stereological quantification of mature oligodendrocytes in the body of 573 the corpus callosum at P21 (prior to seizure onset) and P45 (after seizures are well-established 
574 in $S c n 8 a^{+/ m u t}$ mice) in Scn8a $a^{+/ m u t}$ and $S c n 8 a^{+/+}$mice. Data represent mean \pm SEM; each dot

575 represents one animal. For each P21 mouse, 380 - 748 mature oligodendrocytes were counted;

576 for each P45 mouse, 555-2226 mature oligodendrocytes were counted (P21, Scn8a ${ }^{+/+} n=4$ mice;

$577 S c n 8 a^{+/ m u t} n=3$ mice. P45, Scn8a $a^{+/+} n=8$ mice; Scn8a $a^{+/ m u t} n=6$ mice).

578

579 For all panels in this figure, data were analyzed with ANOVA with post-hoc Sidak's test, correcting

580 for multiple comparisons. ${ }^{*} p<0.05,{ }^{* *} p<0.01,{ }^{* *} p<0.001$, n.s. $=p>0.05$.

581 
Figure 5: Increased callosal myelination after seizure onset in Scn8a ${ }^{+/ m u t}$ mice.

A

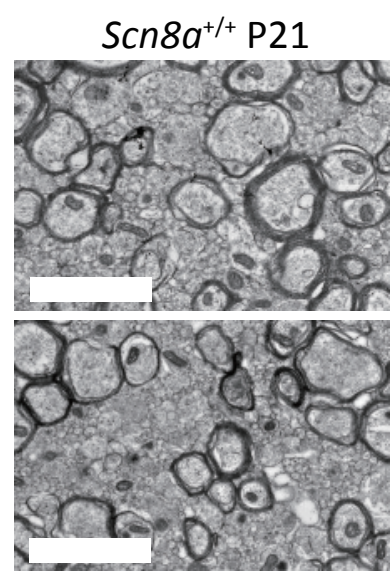

Scn $8 a^{+/ m u t}$ P21

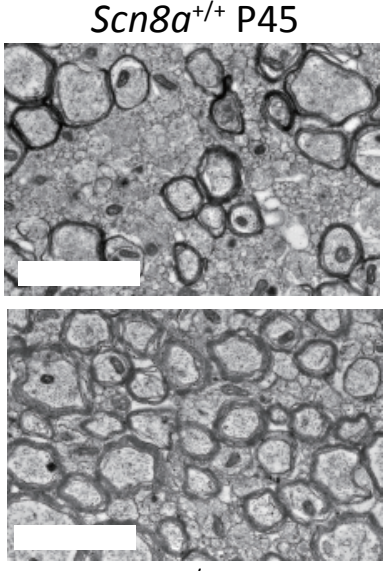

Scn $8 a^{+/ m u t} \mathrm{P} 45$
C

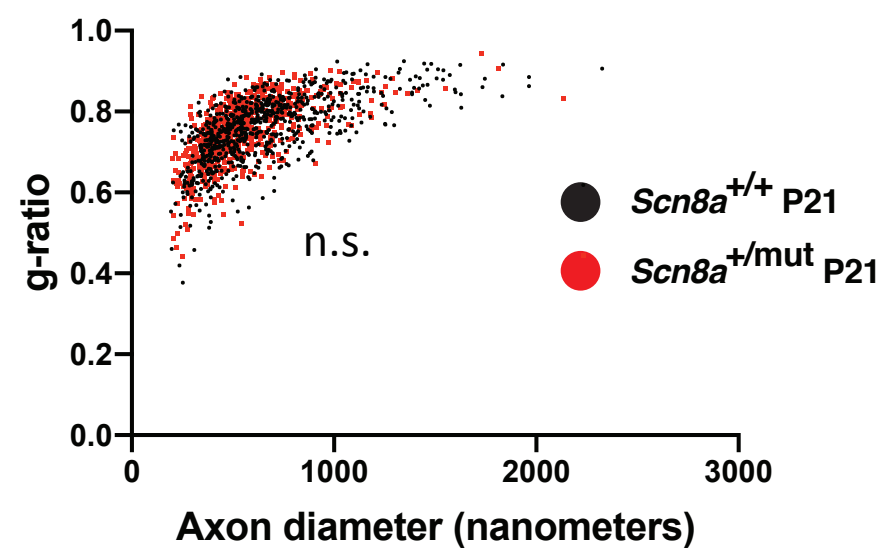

E

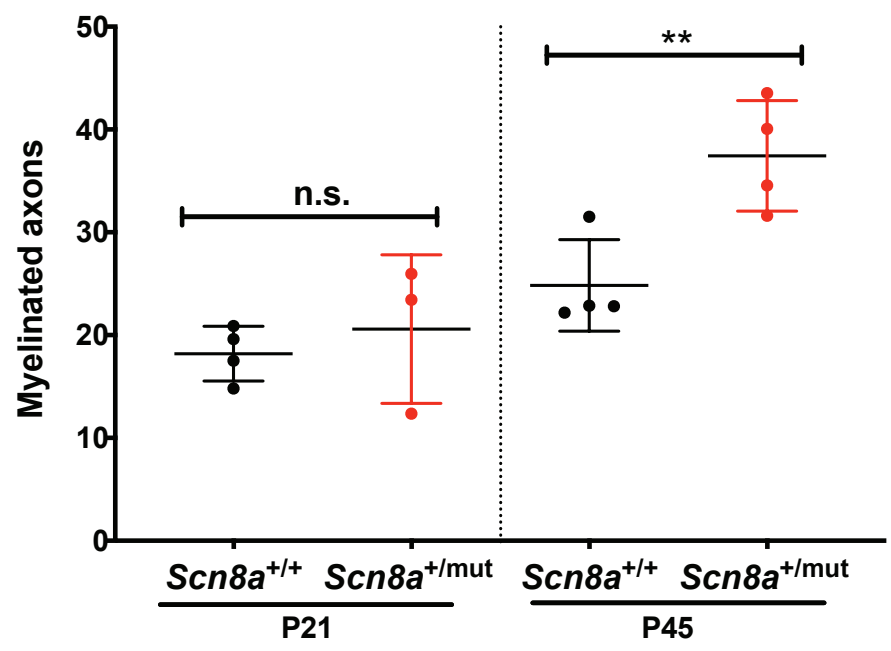

B

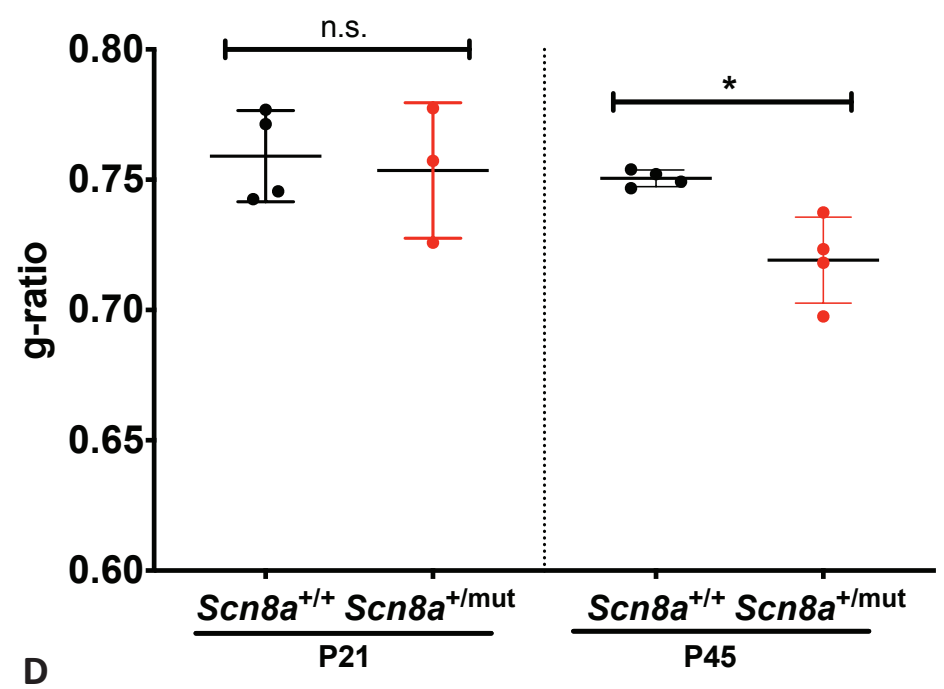

F

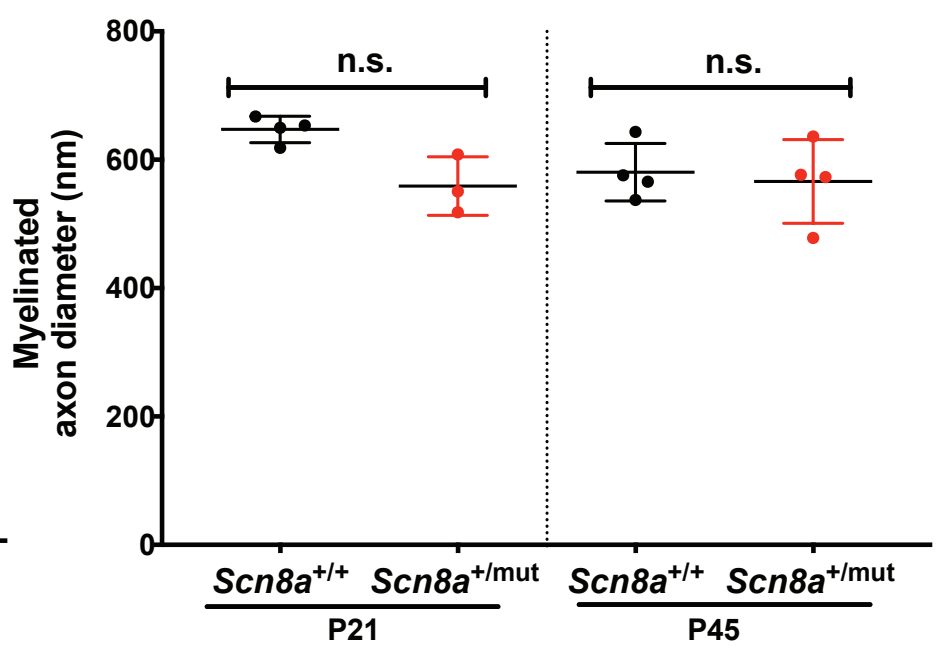


Figure 5: Increased callosal myelination after seizure onset in Scn8a ${ }^{+/ m u t}$ mice.

583 (A) Representative transmission electron microscopy images of myelinated axons in the body of

584 the corpus callosum of P21 (left) and P45 (right) Scn8a+/+ (upper panels) and Scn8a ${ }^{+/ m u t}$ mice

585 (lower panels). Scale bar $=2$ micrometers.

586 (B) Quantitative analysis of myelin sheath thickness (g-ratio) in the body of the corpus callosum

587 in at P21 (prior to seizure onset) and P45 (after seizures are well-established in Scn8a ${ }^{+/ m u t}$ mice),

588 in $\mathrm{Scn}_{8 a^{+/ m u t}}$ (red dots) and $\mathrm{Scn} 8 a^{+/+}$mice (black dots). Data represent mean $\pm \mathrm{SEM}$; each dot

589 represents the mean g-ratio for one animal. For each mouse, 145-298 axons were quantified

590 from at least 15 fields. (P21, Scn8a ${ }^{+/+} n=4$ mice; Scn8a $a^{+/ m u t} n=3$ mice. $P 45, S c n 8 a^{+/+} n=4$ mice;

$591 S c n 8 a^{+/ m u t} n=4$ mice). Data were analyzed by ANOVA with post-hoc Sidak's test.

592 (C-D) Scatterplot of individual axon g-ratio measurements from P21 (C) and P45 (D) mice, as a

593 function of axon diameter, as in (B). Each data point represents one axon, with Scn8a ${ }^{+/+}$axons in

594 black and Scn8a $a^{+/ m u t}$ axons in red. (P21, Scn8a $a^{+/+} n=4$ mice; Scn8a $a^{+/ m u t} n=3$ mice. P45, Scn8a

$595 \mathrm{n}=4$ mice; Scn8a $a^{+/ m u t} \mathrm{n}=4$ mice).

596 (E) Myelinated axon number was quantified using transmission electron microscopy, in the body

597 of the corpus callosum in P21 mice (prior to seizure onset) and P45 mice (with established

598 seizures). Myelinated axon number was normalized to corpus callosum volume (Supplemental

599 Figure 3). Each data point represents mean myelinated axons for one mouse, with black dots

600 indicating $S c n 8 a^{+/+}$and red dots indicating $S c n 8 a^{+/ m u t}$. For each mouse, axon number was

601 quantified in 10 separate fields. Data represent mean \pm SEM; data were analyzed with ANOVA

602 followed by Sidak's testing. (P21, Scn8a ${ }^{+/+}=4$ mice; Scn $8^{+/ m u t}=3$ mice. P45, Scn8a $a^{+/+} 4$ mice;

$\left.603 S \mathrm{Scn} 8 \mathrm{a}^{+/ \mathrm{mut}}=4 \mathrm{mice}\right)$.

604 (F) Myelinated axon diameters were quantified from transmission electron micrographs; black

605 dots indicate $\operatorname{Scn} 8 \mathrm{a}^{+/+}$and red dots indicate $\operatorname{Scn} 8 \mathrm{a}^{+/ \mathrm{mut}}$. Each dot represents the mean myelinated

606 axon diameter from one mouse, with mean \pm SEM indicated. Data were analyzed with ANOVA 
607 followed by Sidak's testing. (P21, Scn8a $a^{+/+} n=4$ mice; Scn8a $a^{+/ m u t} n=3$ mice; P45, Scn8a ${ }^{+/+} n=4$

608 mice, Scn8a ${ }^{+/ m u t} \mathrm{n}=4$ mice.)

609

610 For all panels in this figure, ${ }^{*} p<0.05,{ }^{* *} p<0.01,{ }^{* *} p<0.001$, n.s. $=p>0.05$

611 
Figure 6: Activity-dependent myelination contributes to epileptogenesis.
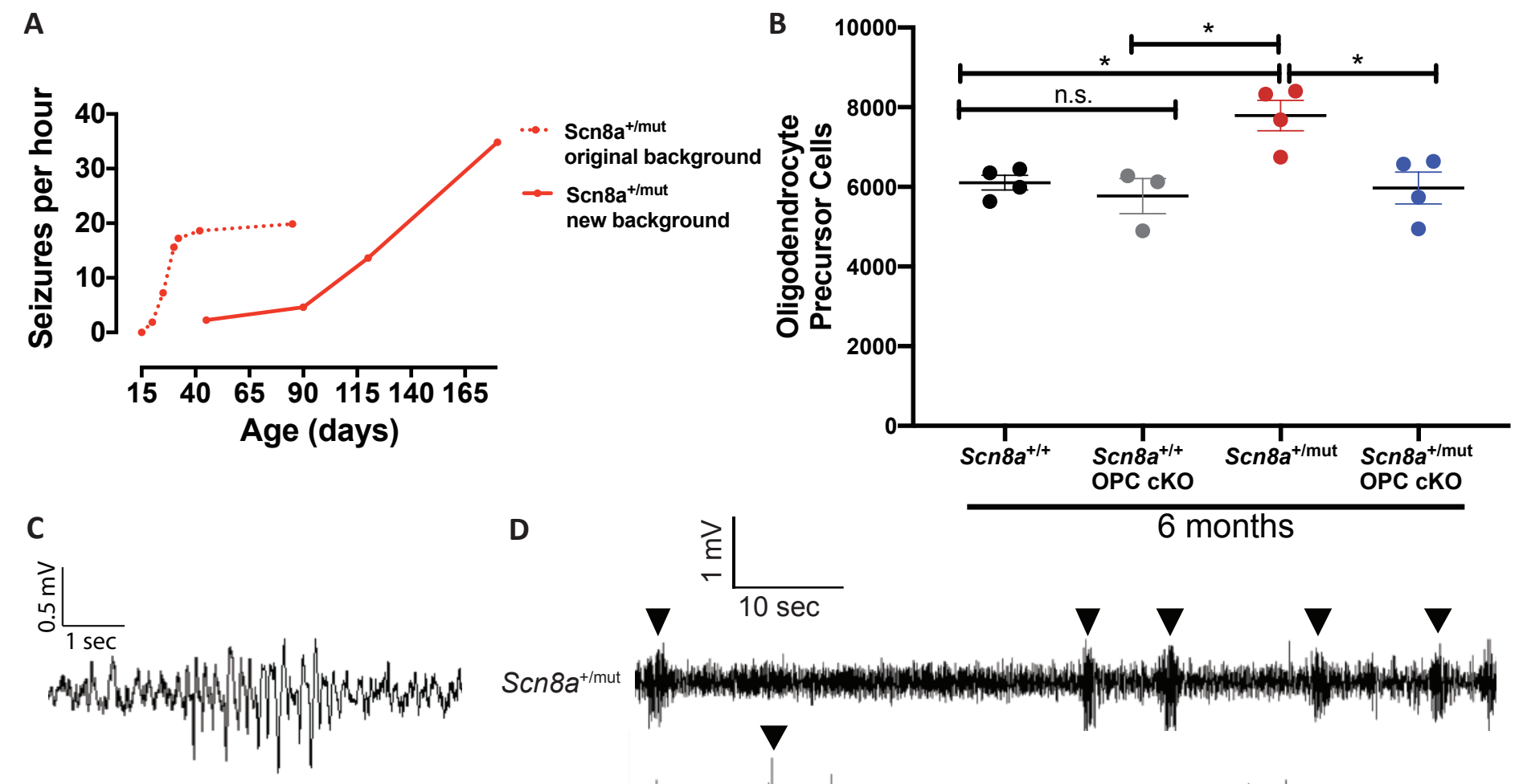

D $\left.\quad \stackrel{\gtrless}{\leftarrow}\right|_{10 \mathrm{sec}}$

E

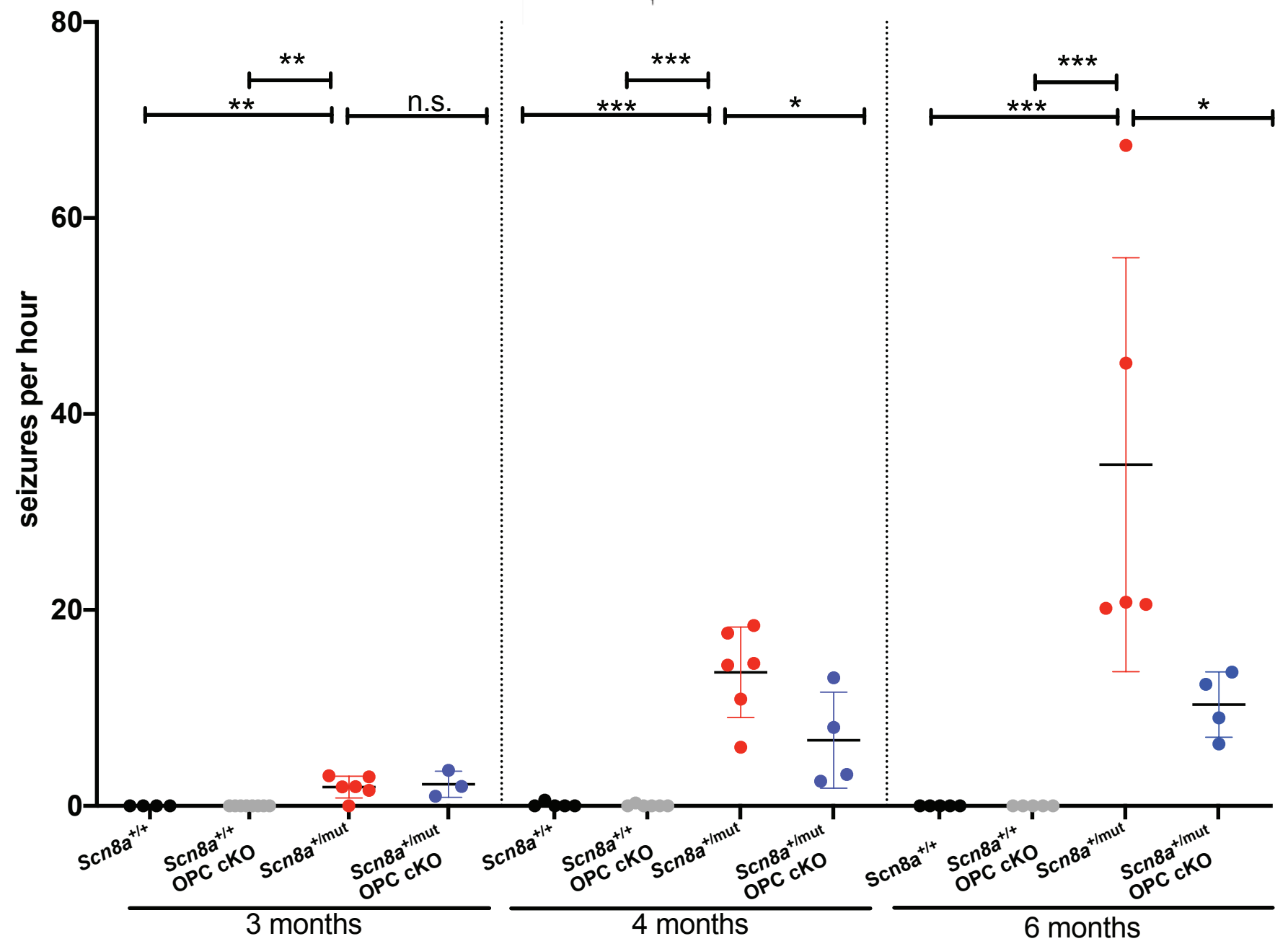


612 Figure 6: Activity-dependent myelination contributes to epileptogenesis.

613 (A) Epileptogenesis occurs later in Scn8a ${ }^{+/ m u t}$ mice on a mixed genetic background. In order

614 to determine the role of activity-dependent myelination in epileptogenesis that occurs in $\mathrm{Scn} 8 \mathrm{a}^{+/ \mathrm{mut}}$

615 mice (originally on a C3HeB/FeJ background), we generated Scn8a ${ }^{+/ m u t}$ mice with floxed TrkB

616 receptor genes and the presence or absence of Cre under the PDGFR $\alpha$ promotor (PDGFR $\alpha-$

617 CreER). All mice underwent treatment with Tamoxifen; only mice expressing Cre subsequently

618 underwent deletion of the TrkB receptor from OPCs. In mice with intact activity dependent

619 myelination (Scn8a ${ }^{+/ m u t}$, TrkB $^{\text {fl/fl }}$, Cre negative; C3HeB/FeJ and C57/BL6 mixed background; solid

620 red line) we observed that seizure onset and progression occurred later time-points (P45-P180,

621 i.e. $1.5-6$ months), relative to the original $S c n 8 a^{+/ m u t}$ line (on a C3HeB/FeJ background) in which

622 seizures begin at P21 and increase until P35-P45 (dashed red line, from Makinson et al, 2017).

623 (B) Genetic blockade of activity-dependent myelination prevents the oligodendroglial

624 response to seizures. Unbiased stereological assessment of OPC number (PDGFR $\alpha-$

625 expressing cells) in 6-month-old wild-type littermates with or without TrkB OPC expression

$626\left(\mathrm{Scn}_{8 a^{+/+}}\right.$and Scn8a ${ }^{+/+}$OPC cKO, respectively), and Scn8a ${ }^{+/ m u t}$ and Scn8a ${ }^{+/ m u t}$ OPC cKO mice.

627 Data represent mean \pm SEM and were analyzed with ANOVA followed by Tukey-Kramer test,

628 adjusting for multiple comparisons. Each dot represents one mouse; 123-273 OPCs were counted

629 from hemi-brains for each mouse. Scn8a+/+ (black dots), $n=4$ mice; Scn $8 a^{+/+}$OPC cKO (gray

630 dots), $\mathrm{n}=3$ mice; Scn8a $a^{+/ m u t}$ (red dots), $\mathrm{n}=4$ mice, Scn8a $a^{+/ m u t}$ OPC cKO (blue dots), $\mathrm{n}=4$ mice.

631 (C-D) Representative spike-wave discharge seizure in a Scn8a ${ }^{+/ m u t}$ mouse $@$ and representative 632 continuous EEG recordings from Scn8a $a^{+/ m u t}$ and Scn8a $a^{+/ m u t}$ OPC cKO mice (D).

633 (E) Blockade of activity-dependent myelination decreases seizure frequency. Quantitative

634 analysis of seizure frequency from EEGs. Each data point represents mean seizures per hour for 635 one mouse, show with group mean \pm SEM. 3 month old time-point: Scn8a+/+ (black dots), n=4 636 mice; Scn8a $a^{+/+}$OPC cKO (gray dots), $n=8$ mice; Scn8a $a^{+/ m u t}$ (red dots), $n=6$ mice,; Scn8a $a^{+/ m u t}$ OPC 
637 cKO (blue dots), n=3 mice. 4-month-old time-point: Scn8a+/+ (black dots), n=5 mice; Scn8a ${ }^{+/+}$

638 OPC cKO (gray dots), $\mathrm{n}=6$ mice; Scn8a $a^{+/ m u t}$ (red dots), n=6 mice, Scn8a ${ }^{+/ m u t}$ OPC cKO (blue

639 dots), n=4 mice. 6-month time-point: Scn8a+/+ (black dots), n=5 mice; Scn8a ${ }^{+/+}$OPC cKO (gray

640 dots), $\mathrm{n}=5$ mice; Scn8a ${ }^{+/ m u t}$ (red dots), n=5 mice,; Scn8a ${ }^{+/ m u t}$ OPC cKO (blue dots), $\mathrm{n}=4$ mice.

641 Data represent mean \pm SEM and data within each timepoint were analyzed with ANOVA followed

642 by Tukey-Kramer test, adjusting for multiple comparisons. ${ }^{*} p<0.05,{ }^{* *} p<0.01,{ }^{* *} p<0.001$, n.s. $=$ $643 p>0.05$.

644 
Supplemental Figure 1: Oligodendroglial density increases with absence seizures in Wag/Rij rats.
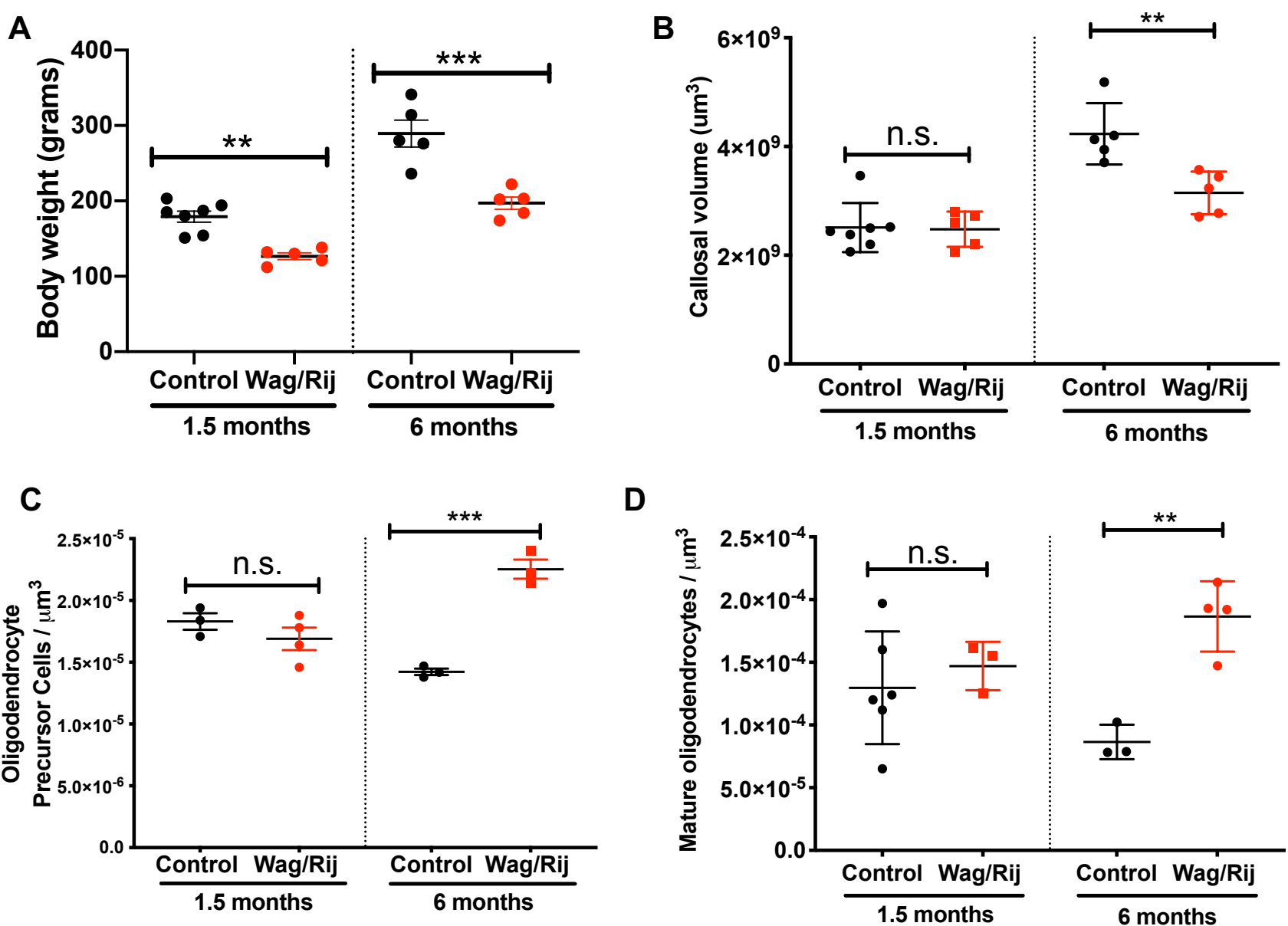

D

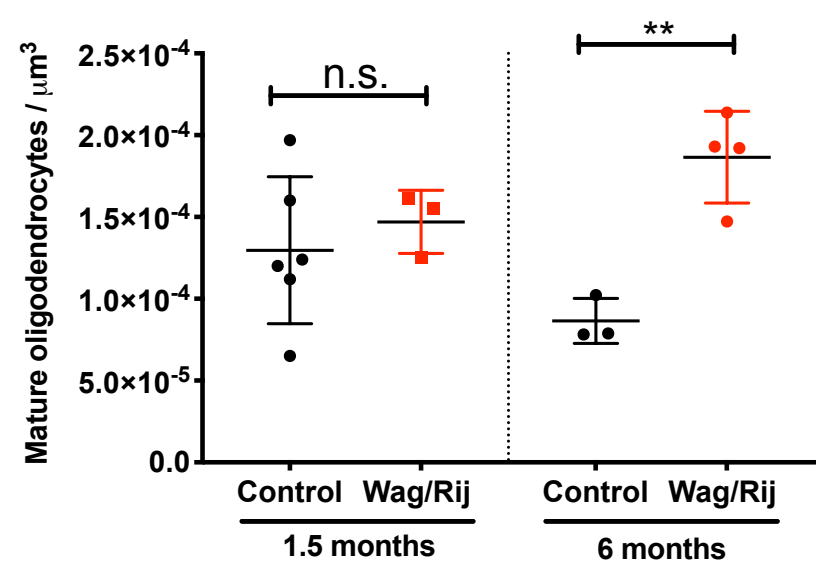


645 Supplemental Figure 1: Oligodendroglial density increases with absence seizures in

646 Wag/Rij rats.

\section{Related to Figure 1}

648 (A) Control (Wistar; black dots) and Wag/Rij (red dots) rats were weighed at 1.5 and 6 months of 649 age. Each dot is the weight in grams for one animal; data represent mean \pm SEM. Data were 650 analyzed by ANOVA followed by Sidak's post-hoc testing (1.5-month timepoint: control =7 rats; 651 Wag/Rij =5. 6-month timepoint: control $=5$ rats, Wag/Rij $=5$ ).

652 (B) The volume of the body of the corpus callosum was computed with Cavalieri's method in 653 control (black dots) and Wag/Rij rats (red dots). Each dot is the callosal volume for one rat; data 654 represent mean \pm SEM. Data were analyzed by ANOVA followed by Sidak's post-hoc testing. 655 (1.5-month timepoint: control =7 rats; Wag/Rij $=5.6$-month timepoint: control $=5$ rats, $\mathrm{Wag} / \mathrm{Rij}=$ $6565)$.

657 (C) Unbiased stereological assessment of OPC density (OPC number normalized to callosal 658 volume). OPCs were defined as cells expressing PDGFR $\alpha$ and Olig2. Each dot is the OPC density 659 for one mouse; data represent mean \pm SEM. Data were analyzed by ANOVA followed by Sidak's 660 post-hoc testing. (1.5-month timepoint: control $=3$ rats; Wag/Rij $=4.6$-month timepoint: control = 6613 rats, Wag/Rij $=3)$.

662 (D) Unbiased stereological assessment of mature oligodendrocyte density. Mature 663 oligodendrocytes expressed Olig2 and CC1 but not PDGFR $\alpha$. Each dot is the oligodendrocyte 664 density for one rat; data represent mean \pm SEM. Data were analyzed by ANOVA followed by 665 Sidak's post-hoc testing. (1.5-month timepoint: control $=6$ rats; Wag/Rij $=3.6$-month timepoint: 666 control $=3$ rats, Wag/Rij $=4$ ). 
Supplemental Figure 2: Myelinated axon diameters do not contribute to $g$-ratio differences in Wag/Rij and control rats.

A

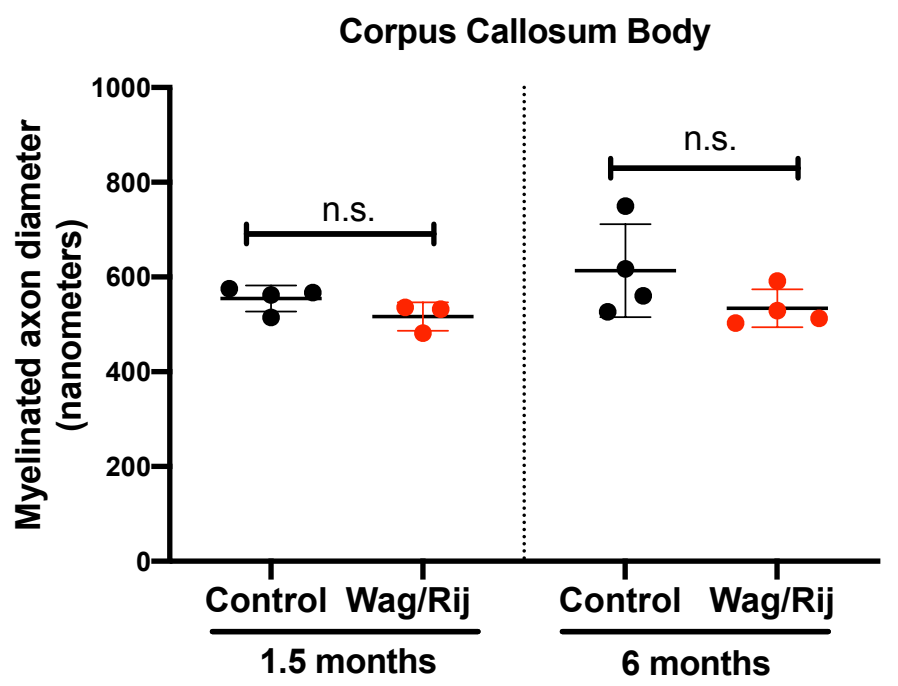

B

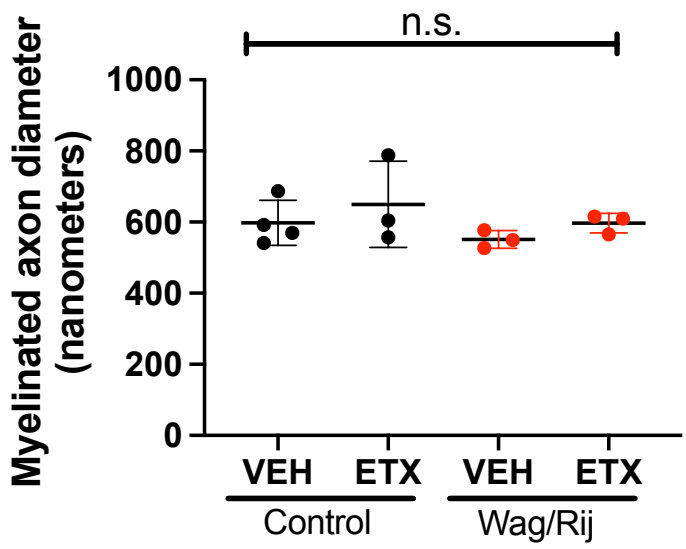


668 Supplemental Figure 2: Myelinated axon diameters do not contribute to g-ratio differences

669 in Wag/Rij and control rats.

$670 \quad$ Related to Figure 2.

671 (A) Mean myelinated axon diameter in the body of the corpus callosum in control (black dots) and

672 Wag/Rij (red dots) rats at 1.5 and 6 months of age. 1.5 month timepoint, $n=4$ control, 3 Wag/Rij;

6736 month timepoint, $n=4$ control, 4 Wag/Rij rats. Data were analyzed with ANOVA with post-hoc

674 Sidak's testing and represent mean \pm SEM; each dot represents one animal.

675 (B) Control and Wag/Rij rats exhibit similar axon diameter, with and without ethosuximide (ETX)

676 treatment. Mean myelinated axon diameter at 7 months of age in control (black dots) and Wag/Rij

677 (red dots) rats treated with vehicle $(\mathrm{VEH})$ or ETX. (Control-VEH, $\mathrm{n}=4$; Control-ETX, $\mathrm{n}=3$;

678 Wag/Rij-VEH, $n=3 ;$ Wag/Rij-ETX, $n=3$ ). Data represent mean \pm SEM and were analyzed by

679 ANOVA with Tukey-Kramer post-hoc testing.

680 
Supplemental Figure 3: Increased oligodendroglial density in the absence seizure network of $\operatorname{Scn} 8 \mathrm{a}^{+/ \mathrm{mut}} \mathrm{mice}$.

A
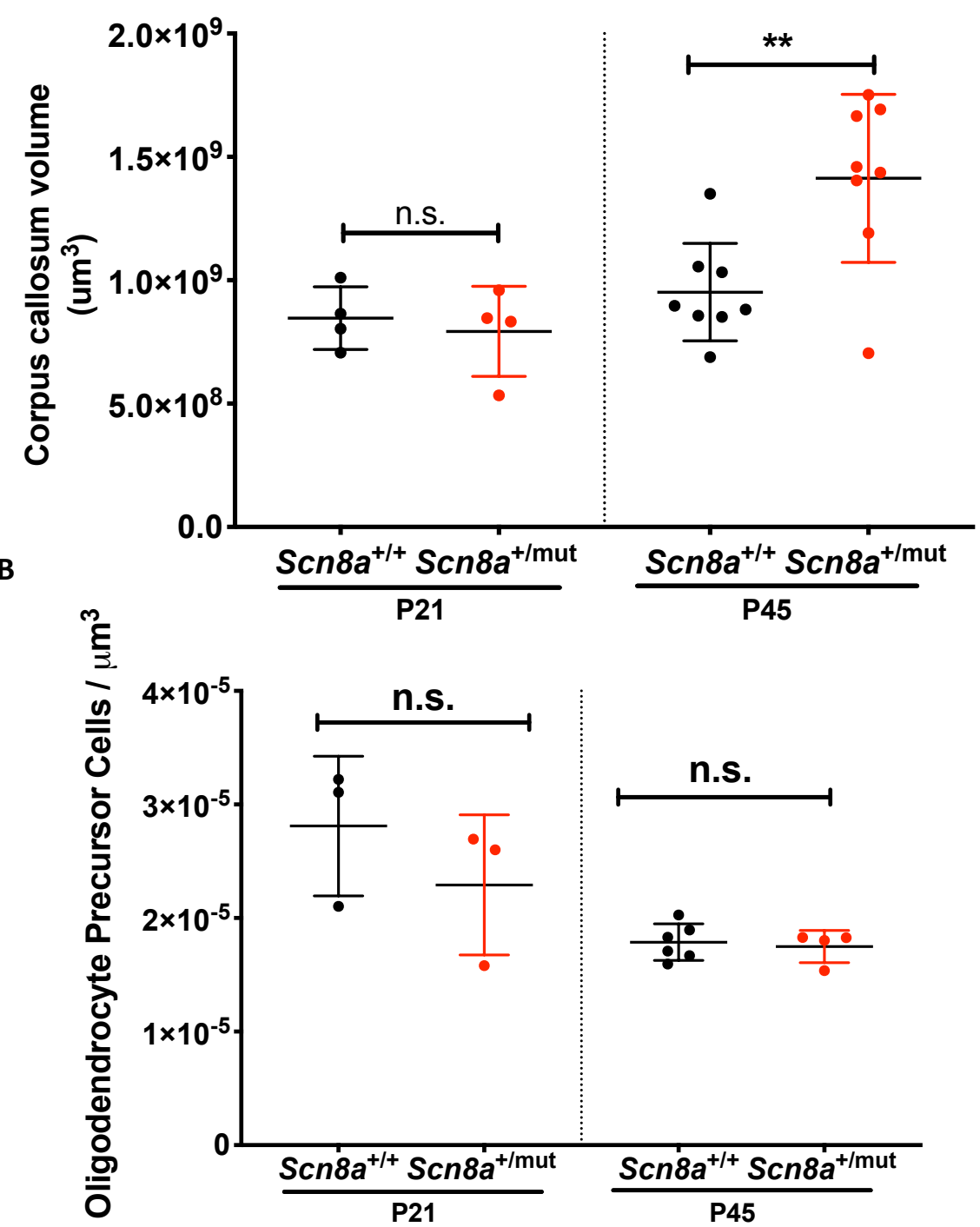

C

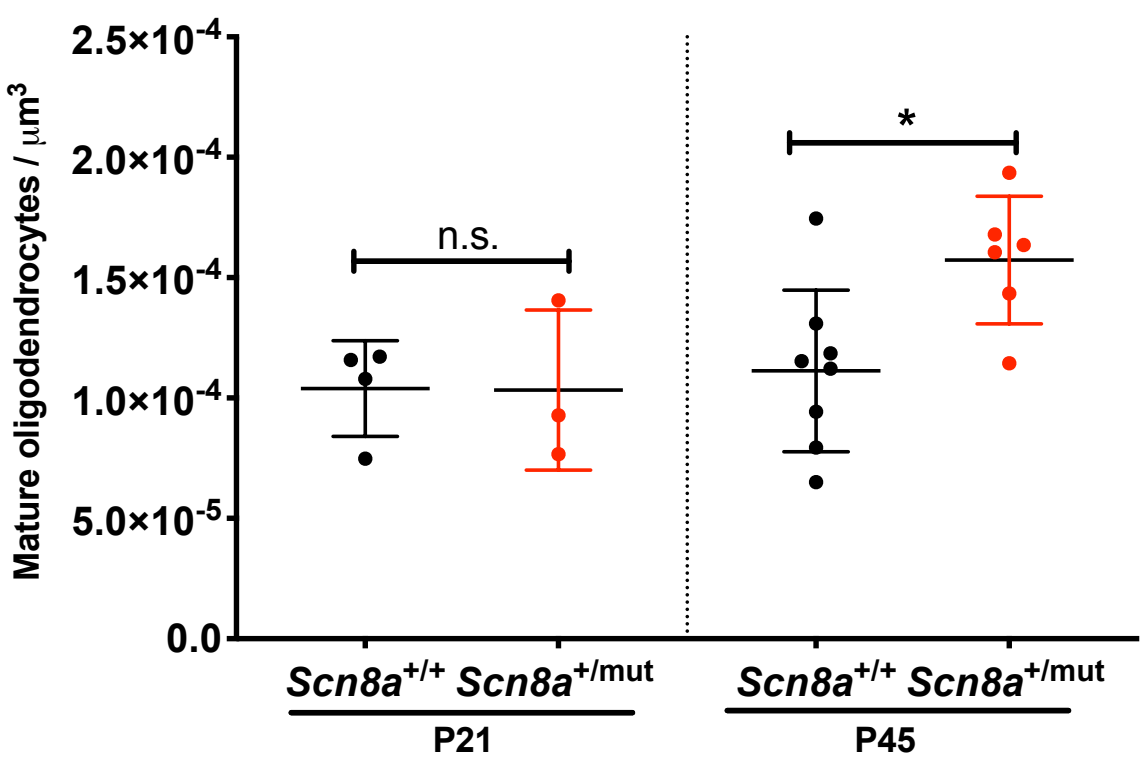


681 Supplemental Figure 3: Increased oligodendroglial density in the absence seizure network

682 of Scn8a $a^{+/ m u t}$ mice.

$683 \quad$ Related to Figure 4.

684 (A) The volume of the body of the corpus callosum was computed with Cavalieri's method in $685 S \operatorname{Scn} 8 a^{+/+}$mice (black dots) and Scn8a/mut mice (red dots). Each dot is the callosal volume for one 686 mouse; data represent mean \pm SEM. (1.5-month timepoint: $S c n 8 a^{+/+}=4$ mice; Scn $8 a^{+/ m u t}=4$ mice.

687 Six-month timepoint: Scn8a $a^{+/+}=8$ mice, $\operatorname{Scn} 8 a^{+/ m u t}=8$ mice).

688 (B) Unbiased stereological quantification of OPC density (cells co-expressing PDGFR $\alpha$ and Olig2) in the body of the corpus callosum P21 (prior to seizure onset) and P45 (after seizures are well-established in Scn8a $a^{+/ m u t}$ mice). $\left(P 21, S c n 8 a^{+/+} n=3 ; S c n 8 a^{+/ m u t} n=3 . P 45, S c n 8 a^{+/+} n=6\right.$;

$\left.691 S c n 8 a^{+/ m u t} n=4\right)$. Black dots represent wildtype littermates $\left(S c n 8 a^{+/+}\right)$while red dots represent $692 S c n 8 a^{+/ m u t}$ mice. Data represent mean \pm SEM; each dot represents the OPC density for one 693 animal.

694 (C) Unbiased stereological quantification of mature oligodendrocyte density (cells co-expressing $695 \mathrm{CC} 1$ and Olig2) in the body of the corpus callosum of Scn8a ${ }^{+/+}$(black dots) and Scn8a ${ }^{+/ m u t}$ mice 696 (red dots) at P21 and P45. (P21, Scn8a $a^{+/+} n=4 ; S c n 8 a^{+/ m u t} n=3 . P 45, S c n 8 a^{+/+} n=8 ; S c n 8 a^{+/ m u t}$ $697 n=6$ ). Data represent mean \pm SEM; each dot represents the oligodendrocyte density of one 698 animal.

699

700 For all panels in this figure, data were analyzed with ANOVA with post-hoc Sidak's testing with 701 correction for multiple comparisons. ${ }^{*} p<0.05,{ }^{* *} p<0.01,{ }^{* * *} p<0.001$, n.s. $=p>0.05$. 
Supplemental Figure 4: Activity-dependent myelination does not impact seizure duration.

n.s.

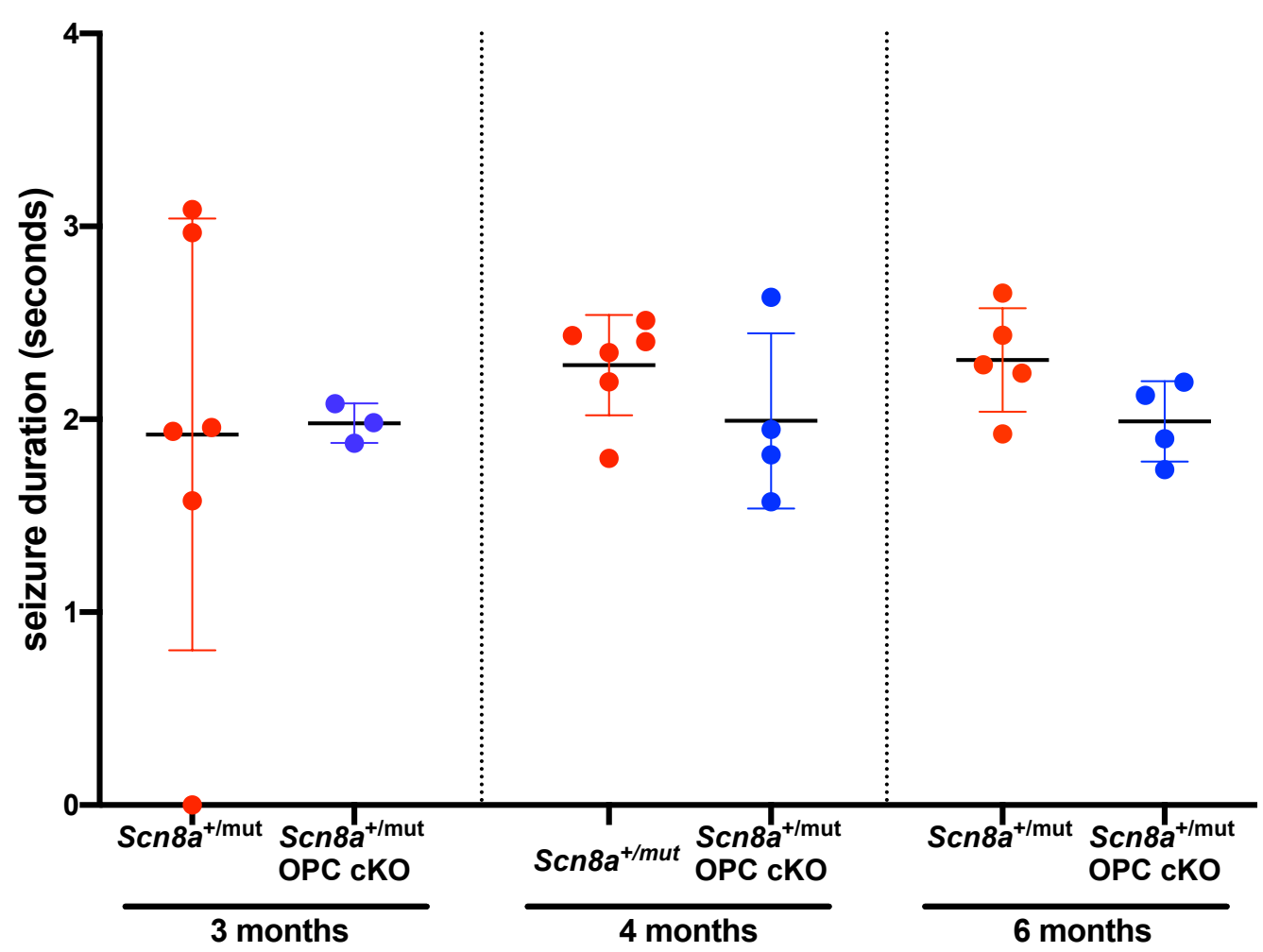


703 Supplemental Figure 4: Activity-dependent myelination does not impact seizure duration.

704 Related to Figure 6.

705 Mean seizure duration was quantified in $\operatorname{Scn} 8 a^{+/ m u t}$ (red dots) and Scn8a ${ }^{+/ m u t}$ OPC cKO mice (blue

706 dots). 3-month-old time-point: Scn8a $a^{+/ m u t} \mathrm{n}=6$ mice, Scn8a ${ }^{+/ m u t}$ OPC cKO, $\mathrm{n}=3$ mice. 4-month-old

707 time-point: Scn8a $a^{+/ m u t}, n=6$ mice, $S c n 8 a^{+/ m u t}$ OPC cKO, n=4 mice. 6-month time-point: $S c n 8 a^{+/ m u t,}$

$708 \mathrm{n}=5$ mice, Scn $8 a^{+/ m u t}$ OPC $c K O, n=4$ mice. Data represent mean \pm SEM and data were analyzed

709 with ANOVA followed by Sidak's test.

710 


\section{STAR Methods}

\section{LEAD CONTACT}

713 Further information and requests for resources and reagents should be directed to and will be

714 fulfilled by the Lead Contact, Michelle Monje (mmonje@stanford.edu).

\section{MATERIALS AVAILABILITY}

- This study did not generate new unique reagents.

DATA AND CODE AVAILABILITY

- $\quad$ The MATLAB code used for EEG analysis in this study is available from the corresponding authors on request.

- Data will be available on Mendeley in the final version of the manuscript and are also

\section{EXPERIMENTAL MODEL AND SUBJECT DETAILS}

\section{Rodent colony maintenance}

727 All experiments were conducted in accordance with protocols approved by the Stanford University

728 Institutional Animal Care and Use Committee (IACUC). Mice or rats were group or single housed

729 (up to 5 mice or 2 rats per cage) according to standard guidelines with ad libitum access to food

730 and water in a $12 \mathrm{~h}$ light/dark cycle. No animals were manipulated other than as reported for that

731 experimental group, i.e., there was no history of drug exposures, surgeries or behavioral testing

732 for the animals used other than that reported for the given experimental group. Mice and rats were 733 healthy and tolerated all experimental manipulations well.

The ages of all mice and rats used in specific studies are indicated in the figures and

735 throughout the text. Briefly, in studies using Wag/Rij and control rats, 1.5-month-old animals were 
737 endpoints after seizures are well established. In studies using Scn8a ${ }^{+/ m u t}$ mice and wild-type

738 littermates, post-natal day $(P) 21$ mice were used to assess endpoints prior to epileptogenesis,

739 while p45 mice were used to assess endpoints after seizures are well established. In studies in

740 which $\mathrm{Scn}_{8 a^{+/ m u t}}$ and other mouse lines were bred (e.g. Figure 6), because seizure onset is

741 delayed, later time points (3 to 6 months) were used to study seizure progression, as described

742 in detail in the text and methods below.

743 Both males and females (rats and mice) were used in equal numbers whenever possible.

744 There was no impact of male or female sex upon any of the endpoints. For the majority of 745 experiments, individual animals utilized came from $\geq 2$ distinct litters.

\section{Wag/Rij rats}

748 Wistar (control) and Wag/Rij rats were purchased from Charles Rivers Laboratories (Wistar: cat 749 \#003; Wag/Rij, Charles Rivers Italy: strain code \#638). A colony of Wag/Rij rats has subsequently 750 been maintained in Dr. Huguenard's lab at Stanford (Sorokin et al., 2017).

\section{Scn8a $a^{+/ m u t}$ mice and Scn8a $a^{+/ m u t}$ OPC cKO mice}

$753 \mathrm{Scn}_{8} \mathrm{a}^{+/ \mathrm{mut}}$ mice with the med loss of function mutation in Scn8a (C3Fe.Cg-Scn8amed/J, 754 jax.org/strain/003798; Makinson et al, 2017) were bred to wild-type mice (Scn8a $\left.{ }^{+/+}\right)$on a congenic 755 background strain (C3HeB/FeJ, jax.org/strain/00658). In separate studies, successive breeding 756 was performed to obtain mice with absence seizures $\left(S c n 8 a^{+/ m u t}\right)$ and inducible deletion of the 757 TrkB receptor from OPCs, enabling blockade of activity-dependent myelination $\left(S c n 8 a^{+/ m u t}\right.$;

758 TrkB ${ }^{\mathrm{fl} / \mathrm{fl}} ;$ PDGFR $\alpha:$ Cre-ER). Specifically, Scn8a ${ }^{+/ m u t}$ mice on the C3HeB/FeJ background were 759 crossed with mice expressing a "floxed" TrkB gene (TrkB $\left.{ }^{\mathrm{fl} / \mathrm{fl}}\right)$ on a C57/BL6 background to obtain

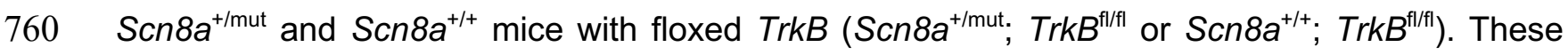
761 mice were crossed with mice with floxed TrkB and tamoxifen inducible Cre under the PDGFRa 
762 promotor (TrkB $B^{\mathrm{fl} / \mathrm{fl}} ;$ PDGFR $\alpha:$ :Cre-ER), also on a C57/BL6 background. Both the PDGFR $\alpha:$ Cre-

763 ER (originally acquired from The Jackson Laboratory, jax.org/strain/018280) and TrkB $B^{\mathrm{fl} / \mathrm{fl}}$

764 (originally acquired form MMRRC at UC Davis, strain \# 033048-UCD) mouse lines are maintained

765 in our laboratory, and are described in previously published work (Geraghty et al., 2019).

Mice were treated with Tamoxifen (Sigma-Aldrich, T5648) $100 \mathrm{mg} / \mathrm{kg}$ IP for 3 days (p21p23) which induces robust Cre expression and deletion of the TrkB receptors from OPCs in TrkB ${ }^{\mathrm{fl} / f l}$; PDGFR $\alpha:$ Cre-ER mice but not mice lacking Cre (TrkB ${ }^{\mathrm{fl} / \mathrm{fl}}$ only)(Geraghty et al., 2019).

\section{Genotyping}

At P10, mice were ear and/or tail clipped and DNA was extracted using the REDExtract-N-Amp ${ }^{\mathrm{TM}}$

773 Tissue PCR Kit (Sigma-Aldrich, Cat\# XNAT-100RXN). A master mix of REDEX reagent, primers

774 as indicated below, water, and extracted DNA from each animal were created for a total volume

775 of $20 \mu \mathrm{L}$ for each animal. For detection of the floxed TrkB allele, the following primers (acquired

776 from IDT) were used: TrkB fl/fl F: ATGTCGCCCTGGCTGAAGTG; TrkB fl/fl R:

777 ACTGACATCCGTAAGCCAGT. The PCR protocol was $94^{\circ} \mathrm{C}$ for 3 minutes $\times 1$; then $94^{\circ} \mathrm{C}$ for 1

778 minute; $65^{\circ} \mathrm{C}$ for 1.5 minutes; $72^{\circ} \mathrm{C}$ for 1.5 minutes all $x 40$ cycles; then $72^{\circ} \mathrm{C}$ for 7 mins $x 1$. The

779 PCR products were run on a $1.8 \%$ agarose gel and a band size of $450 \mathrm{bp}$ indicated the presence

780 of the floxed allele. For detection of Cre, the following primers (IDT) were used: Cre Up: GAT CTC

781 CGG TAT TGA AAC TCC AGC; Cre Down: GCT AAA CAT GCT TCA TCG TCG G. PCR protocol

782 was $94^{\circ} \mathrm{C}$ for 5 minutes $\times 1 ; 94^{\circ} \mathrm{C} \times 15$ seconds, $65^{\circ} \mathrm{C} \times 30$ seconds, dropping $1^{\circ} \mathrm{C}$ after each

783 cycle until the last cycle occurred at $55^{\circ} \mathrm{C}$, all $\times 10$ cycles; then $72^{\circ} \mathrm{C}$ for 40 seconds $\times 1$ cycle.

784 The presence of a 650 bp PCR product on a $1.8 \%$ agarose gel indicated an animal positive for 785 the PDGFR $\alpha:$ :Cre gene. Automated genotyping for the $S c n 8 a^{\text {med }}$ allele was done using tail 786 samples via Transnetyx, Inc (www.transnetyx.com). 


\section{Ethosuximide treatment paradigm}

790 Wistar (control) and Wag/Rij rats were treated with ethosuximide (ETX) or vehicle on a previously

791 published dosing schedule (Blumenfeld et al., 2008) shown to prevent and/or significantly reduce

792 seizures. Male and female littermates were randomly assigned to either vehicle or ETX treatment.

793 Pharmaceutical grade ETX solution (Akorn Pharmaceuticals, 250 mg/mL, NDC: 61748-024-16)

794 was added to drinking water in bottles that were shielded from light, at a concentration of 2.5

$795 \mathrm{mg} / \mathrm{mL}$ leading to approximately dosing of $300 \mathrm{mg} / \mathrm{kg} /$ day dosing (Blumenfeld et al., 2008). The

796 solution was changed at least every 7 days and the health, weight and drinking of animals was

797 monitored regularly throughout the study. Prior to perfusion, 1-2 $\mathrm{mL}$ of blood was taken. The

798 samples were centrifuged at 2000rpm, 4 degrees $C$, for 5 minutes and plasma was collected for

799 measurement of ETX concentration using liquid chromatography/mass spectroscopy, performed

800 at the Stanford BioADD center (http://med.stanford.edu/bioadd.html).

801

\section{In vivo Electrocorticography (EEG)}

803 Rats were stereotactically implanted with wires attached to screws over the bilateral 804 somatosensory cortices (AP $-3 \mathrm{~mm}, \mathrm{ML} 3.5-4 \mathrm{~mm}$ ), at 6 months of age. Mice were implanted for 805 EEG following tamoxifen administration. Scn8a ${ }^{+/ m u t} ;$ TrkB ${ }^{\mathrm{fl} / \mathrm{fl}} ;$ PDGFRa::Cre-ER mice and their 806 littermates were implanted for EEG with wires (A-M Systems, Cat\#791400) and screws (J.I. 807 Morris, Cat\#FF00CE125) over the bilateral somatosensory cortices (coordinates AP -1.3 mm, ML $808 \quad 1.5-2 \mathrm{~mm})$.

$809 \quad$ Mice and rats were also implanted with a reference wire over cerebellum, and implants 810 were secured with dental cement (Metabond, \#S399, S371, S398; also Jet Set4 Liquid, Lang 811 Dental 3802X6). Implanted wires were integrated into custom-made Mill-Max headpieces (Digi812 Key Electronics, ED90267-ND) that could be connected to a head stage, consisting of a digitizer 813 and amplifier board (Intan Technologies, C3334). Awake and freely behaving animals were 814 tethered to an acquisition board (Open Ephys) with light-weight SPI interface cables (Intan, 
815 C3206). Continuous real-time EEG was recorded with Open Ephys software (https://open-

816 ephys.org). Data were sampled at $2 \mathrm{kHz}$ and bandpass filtered between 1-300Hz. All animals

817 underwent 3-4 hours of continuous EEG recording between the hours of 10am-5pm.

819 Immunohistochemistry

820 Rats were given a lethal dose of Fatal Plus (sodium pentobarbital, Vortech Pharmaceuticals,

821 NDC: $0298-9373-68$ ) and transcardially perfused with $40-80 \mathrm{~mL}$ of ice-cold $0.1 \mathrm{M}$ PBS followed

822 by $40-80 \mathrm{~mL} 4 \%$ paraformaldehyde in PBS before brain extraction and tissue processing. Mice

823 were given a lethal dose of Fatal Plus or 2.5\% Avertin (2,2,2-tribromoethanol, Sigma, T48402)

824 and transcardially perfused with $10-20 \mathrm{~mL}$ of ice-cold PBS followed by $10-20 \mathrm{~mL}$ of $4 \%$

825 paraformaldehyde in PBS. In studies involving ETX-treated rats and Scn8a ${ }^{+/ m u t ;}$ TrkB ${ }^{\text {fl/fl; }}$

826 PDGFRa::Cre-ER mice, brains were bisected in the sagittal plane at the interhemispheric fissure.

827 One half was post-fixed in $4 \%$ paraformaldehyde overnight at $4 \mathrm{C}$ prior to transfer to $30 \%$ sucrose

828 for cryoprotection for several days; the other half was processed for electron microscopy (see

829 below). Cryoprotected brains or hemi-brains were embedded in Tissue-Tek OCT compound

830 (Sakura, 4583) and sectioned in the coronal plane at $50 \mu \mathrm{m}$ using a sliding microtome (Microm

831 HM450; Thermo Scientific). For immunohistochemistry, selected coronal sections were rinsed

832 three times in TBS and incubated in blocking solution (3\% normal donkey serum, Jackson

833 Immunoresearch AB2337258; 0.3\% Triton X-100 in TBS) at room temperature for 30 min. Rabbit

834 anti-Olig2 (1:400, Millipore AB9610), Goat anti-PDGFRa (1:200, R\&D Systems AF1062), mouse

835 anti-APC (CC1,1:50, Calbiochem, OP80), or Rat anti-Ki67 (1:200, Life Technologies, 14-5698-

836 82) were diluted in staining solution (1\% normal donkey serum, $0.3 \%$ Triton $\mathrm{X}-100$ in TBS) and

837 incubated with sections at room temperature for 2.5 days; when staining for $\mathrm{CC} 1$, sections were

838 incubated at $4 \mathrm{C}$ for 10 days. Sections were then rinsed three times in TBS and incubated in

839 secondary antibody solution containing Alexa 488 donkey anti-rabbit IgG (1:500, Jackson Immuno

840 Research, 711-545-152), Alexa 647 donkey anti-goat IgG (1:500, Jackson Immuno Research, 
841 A21447), Alexa 594 donkey anti-mouse IgG (1:500, Jackson Immuno Research, 715-585-150),

842 or Alexa 594 donkey anti-rat IgG (1:500, Jackson Immuno Research, 712-585-153) in staining

843 solution at $4^{\circ} \mathrm{C}$ overnight. Sections were rinsed three times in TBS and mounted with ProLong

844 Gold Mounting medium (Life Technologies, P36930).

\section{Electron microscopy}

847 Rats were given a lethal dose of Fatal Plus (sodium pentobarbital, Vortech Pharmaceuticals 0298-

848 9373-68) and transcardially perfused with $40-80 \mathrm{~mL}$ of ice-cold $0.1 \mathrm{M}$ PBS followed by $40-80 \mathrm{~mL}$

849 Karnofsky fixative, consisting of 4\% PFA (Electron Microscopy Services (EMS), 15700) and 2\%

850 glutaraldehyde (EMS, 16000) in 0.1M sodium cacodylate buffer (EMS, 12300) (Geraghty et al.,

851 2019; Gibson and Monje, 2019; Gibson et al., 2014) in PBS before brain extraction and tissue

852 processing. Mice were given a lethal dose of Fatal Plus or Avertin (Sigma, T4,8402) and

853 transcardially perfused with $10-20 \mathrm{~mL}$ of ice-cold PBS followed by $10-20 \mathrm{~mL}$ of Karnofsky fixative.

854 In experiments where hemi-brains were used, one half was post-fixed in Karnofsky's fixative

855 immediately following perfusion with PBS and 4\% PFA. Samples were post-fixed in Karnofsky

856 fixative for at least 2 weeks. A $\sim 1 \mathrm{~mm}^{3}$ block of tissue was dissected from the midline sagittal

857 corpus callosum at the rostrocaudal location overlying the dentate gyrus and the hippocampal

858 fornix, enabling cross-sectional views of callosal projection axons. The dissected block was

859 processed for transmission electron microscopy as described previously (Gibson et al., 2014).

860 Briefly, tissue was post-fixed in 1\% osmium tetroxide (EMS 19100) for 1 hour at room

861 temperature, washed three times in ultra-filtered water, then en bloc stained for 2 hours at room

862 temperature before dehydration in gradient ethanols, then rinsed in $100 \%$ ethanol twice followed

863 by acetonitrile (Fisher Scientific, A21-1). Samples were then embedded in 1:1 Embed-812 (EMS

864 14120):acetonitrile, followed by EMbed-812 for 2 hours, then placed into TAAB capsules filled

865 with fresh resin before incubation in a $65^{\circ} \mathrm{C}$ oven overnight. $75-90 \mathrm{~nm}$ sections from this block

866 were mounted on Formvar-carbon coated slot grids and contrast stained for 30 seconds in $3.5 \%$ 
uranyl acetate in $50 \%$ acetone (EMS, 10015), followed by $0.2 \%$ lead citrate (EMS, 0378) for 30 seconds. Samples were imaged with a JEOL JEM-1400 transmission electron microscope at

$869120 \mathrm{kV}$ and images were collected with a Gaton Orius digital camera.

871 QUANTIFICATION AND STATISTICAL ANALYSIS

872 Unbiased stereology

873 All quantifications were performed by experimenters blinded to subject identity and experimental 874 condition. OPCs and oligodendrocytes were visualized with an MBF Zeiss Axiocam light 875 microscope. Cell numbers were determined through unbiased stereology using Stereo 876 Investigator software (MBF Bioscience). Regions of interest containing the body of the corpus 877 callosum, beginning rostrally at the level of the hippocampal fornix at the third ventricle, and continuing caudally through the anterior hippocampus (approximate Bregma AP $-0.8 \mathrm{~mm}$ to -3.8 $\mathrm{mm}$ for rats, $-0.8 \mathrm{~mm}$ to $-2 \mathrm{~mm}$ from mice) were traced within sections at $2.5 \mathrm{x}$ magnification. Images were acquired at $63 x$ from every $6^{\text {th }}$ section throughout this region; $40 x$ magnification was

881 used for analyses of Ki67-expressing OPCs. For mice, this included 3-6 sections per animal, while 882 for rats, this included 4-7 sections per animal; there were no differences in the number of sections 883 used between experimental groups. Stereological parameters were determined through pilot 884 studies, ensuring that at least $100-300$ cells would be counted per animal and the Gunderson $885 \mathrm{~m}=1$ coefficient of error was less than 0.1 (Slomianka and West, 2005; West, 2013) (typical CEs 886 were $0.03-0.07)$. In all studies, disector height of $30 \mathrm{~mm}$ and guard zones of $3 \mathrm{~mm}$ were applied 887 unless otherwise indicated. We measured the volume of the body of the corpus callosum (region 888 interrogated for cell counts) with the Cavalieri method (West, 2012). The following stereological 889 parameters were used:

890 - Mouse OPCs: sampling grid size was set to $225 \times 225 \mu \mathrm{m}$; counting frame was set to 100 $\mathrm{x} 100 \mu \mathrm{m}$. 
- Mouse oligodendrocytes: sampling grid: $500 \times 250 \mu \mathrm{m}$; counting frame $100 \times 100 \mu \mathrm{m}$, disector height $20 \mu \mathrm{m}$.

- $\quad$ Rat OPCs: sampling grid size, $300 \times 150 \mu \mathrm{m}$; counting frame $75 \times 75 \mu \mathrm{m}$.

- $\quad$ Rat OPCs in hemibrains (ETX studies): grid size $225 \times 225 \mu \mathrm{m}$; counting frame $100 \times 100$ $\mu \mathrm{m}$.

- $\quad$ Rat Ki67-expressing OPCs: 300 x $175 \mu \mathrm{m}$; counting frame $130 \times 130 \mu \mathrm{m}$.

- Rat oligodendrocytes: $750 \times 350 \mu \mathrm{m}$; counting frame $75 \times 75 \mu \mathrm{m}$; disector height $20 \mu \mathrm{m}$.

900 Quantitative analysis of myelin structure

901 G-ratio, defined as the length of the axonal diameter in its short axis, divided by the diameter of

902 the entire fiber in the same axis (axonal diameter / axonal diameter + myelin sheath), was 903 quantified using ImageJ software (https://imagej.nih.gov/ij/) (Gibson et al., 2014; Steadman et al., 904 2020; Waxman, 1980). Axons were quantified from 4000X transmission electron micrographs.

905 Myelinated axon number was determined by quantifying the number of myelinated axons per

$9064000 x$ electron micrograph and multiplying by the measured volume (in $\mu \mathrm{m}^{3}$ ) of the corresponding 907 region (body) of the corpus callosum. 150-300 axons from 8-20 micrographs were quantified per 908 animal (exact ranges are specified in figure legends).

909

910 EEG analysis

911 EEG data acquired with Open Ephys software was displayed and seizures from 3-4 hours of EEG

912 recording were visually identified, marked and tabulated by a blinded reviewer using custom

913 MATLAB software. Seizures were associated with behavioral arrest, and the corresponding EEG

914 demonstrated predominantly $4-8 \mathrm{~Hz}$ frequency spike wave morphology, amplitude $\sim 1.5-2$ times

915 that of the background, and duration > 1 second (Makinson et al., 2017; Sorokin et al., 2017). 


\section{Statistical analysis}

918 Full details of statistical analyses can be found in the figure legends. For all studies, " $\mathrm{n}$ " refers to

919 the number of mice or rats included in each experimental group, and unless indicated otherwise 920 (e.g. g-ratio scatterplots), each data point in a graph represents the mean from one mouse. For

921 all studies, $\mathrm{n}=3$ or more mice / rats per group, with the exact $\mathrm{n}$ specified in figure legends. Sample

922 sizes were based on the variance of data in pilot experiments, and were generally estimated by

923 power calculations which determined the number of animals " $\mathrm{n}$ " needed for $80 \%$ power to detect

924 a 20-30\% difference between genotypes. GraphPad Prism software (version 8, GraphPad

925 Software, LLC) was used to perform statistical analyses. Statistical significance was defined as $p$

$926<0.05$ throughout. The Wilks-Shapiro test was used to determine whether data were normally

927 distributed; parametric tests were used where indicated. Nonparametric tests were used for

928 nonparametric datasets. For experiments comparing control or Wag/Rij rats, or Scn8a ${ }^{+/+}$and

929 Scn8a $a^{+/ m u t}$ mice at different time points (e.g. Figures 1, 2, 4, 5 and Supplemental Figures 1, 2A,

930 and 3) ANOVA followed by Sidak's post hoc-test, correcting for multiple comparisons, was used

931 to specifically compare groups within specific age groups. When two experimental groups within

932 only one time-point were compared (Figure 1F), a t-test was used. For experiments in which rats

933 were treated with ethosuximide or vehicle (Figure 3), and those studies involving conditional

934 knockout of TrkB from OPCs in Scn8a ${ }^{+/+}$and Scn8a $a^{+/ m u t}$ mice (Figure 6, Supplemental Figure 4),

935 ANOVA with post-hoc Tukey-Kramer testing was employed in order to perform multiple relevant

936 comparisons with appropriate corrections. For comparisons of seizure frequency in rats (Figure

937 3B), the nonparametric Kruskal-Wallis and Dunn's post-hoc tests were used. 
Allen Brain Atlas, atlas.brain-map.org.

Arzimanoglou, A., French, J., Blume, W.T., Cross, J.H., Ernst, J.P., Feucht, M., Genton, P., Guerrini, R., Kluger, G., Pellock, J.M., et al. (2009). Lennox-Gastaut syndrome: a consensus approach on diagnosis, assessment, management, and trial methodology. Lancet Neurol 8, 8293.

Bai, X., Guo, J., Killory, B., Vestal, M., Berman, R., Negishi, M., Danielson, N., Novotny, E.J., Constable, R.T., and Blumenfeld, H. (2011). Resting functional connectivity between the hemispheres in childhood absence epilepsy. Neurology 76, 1960-1967.

Balkowiec, A., and Katz, D.M. (2000). Activity-dependent release of endogenous brain-derived neurotrophic factor from primary sensory neurons detected by ELISA in situ. J Neurosci 20, 7417-7423.

Battefeld, A., Klooster, J., and Kole, M.H. (2016). Myelinating satellite oligodendrocytes are integrated in a glial syncytium constraining neuronal high-frequency activity. Nat Commun 7 , 11298.

Bi, G., and Poo, M. (2001). Synaptic modification by correlated activity: Hebb's postulate revisited. Annu Rev Neurosci 24, 139-166.

Blumenfeld, H., Klein, J.P., Schridde, U., Vestal, M., Rice, T., Khera, D.S., Bashyal, C., Giblin, K., Paul-Laughinghouse, C., Wang, F., et al. (2008). Early treatment suppresses the development of spike-wave epilepsy in a rat model. Epilepsia 49, 400-409. history of typical absence seizures - Petit mal revisited. Epilepsy Behav 80, 346-353. epileptiform activity depends on the astrocytic glutamate-glutamine cycle. J Neurophysiol 102, 2880-2888.

Camfield, P.R. (2011). Definition and natural history of Lennox-Gastaut syndrome. Epilepsia 52 Suppl 5, 3-9.

Cavdar, S., Kuvvet, Y., Sur-Erdem, I., Ozgur, M., and Onat, F. (2019). Relationships between

Chahboune, H., Mishra, A.M., DeSalvo, M.N., Staib, L.H., Purcaro, M., Scheinost, D., Papademetris, X., Fyson, S.J., Lorincz, M.L., Crunelli, V., et al. (2009). DTI abnormalities in anterior corpus callosum of rats with spike-wave epilepsy. Neuroimage 47, 459-466.

Christian, C.A., Herbert, A.G., Holt, R.L., Peng, K., Sherwood, K.D., Pangratz-Fuehrer, S., Rudolph, U., and Huguenard, J.R. (2013). Endogenous positive allosteric modulation of GABA(A) receptors by diazepam binding inhibitor. Neuron 78, 1063-1074. 
974

Christian, C.A., and Huguenard, J.R. (2013). Astrocytes potentiate GABAergic transmission in the thalamic reticular nucleus via endozepine signaling. Proc Natl Acad Sci U S A 110, 2027820283.

Citraro, R., Leo, A., De Caro, C., Nesci, V., Gallo Cantafio, M.E., Amodio, N., Mattace Raso, G., Lama, A., Russo, R., Calignano, A., et al. (2020). Effects of Histone Deacetylase Inhibitors on the Development of Epilepsy and Psychiatric Comorbidity in WAG/Rij Rats. Mol Neurobiol 57, 408-421.

Coenen, A.M., and Van Luijtelaar, E.L. (1987). The WAG/Rij rat model for absence epilepsy: age and sex factors. Epilepsy Res 1, 297-301.

Coenen, A.M., and Van Luijtelaar, E.L. (2003). Genetic animal models for absence epilepsy: a review of the WAG/Rij strain of rats. Behav Genet 33, 635-655.

Cope, D.W., Di Giovanni, G., Fyson, S.J., Orban, G., Errington, A.C., Lorincz, M.L., Gould, T.M., Carter, D.A., and Crunelli, V. (2009). Enhanced tonic GABAA inhibition in typical absence epilepsy. Nat Med 15, 1392-1398.

Coulter, D.A., and Steinhauser, C. (2015). Role of astrocytes in epilepsy. Cold Spring Harb Perspect Med 5, a022434.

Dezsi, G., Ozturk, E., Stanic, D., Powell, K.L., Blumenfeld, H., O'Brien, T.J., and Jones, N.C. (2013). Ethosuximide reduces epileptogenesis and behavioral comorbidity in the GAERS model of genetic generalized epilepsy. Epilepsia 54, 635-643.

Dieni, S., Matsumoto, T., Dekkers, M., Rauskolb, S., lonescu, M.S., Deogracias, R., Gundelfinger, E.D., Kojima, M., Nestel, S., Frotscher, M., et al. (2012). BDNF and its propeptide are stored in presynaptic dense core vesicles in brain neurons. J Cell Biol 196, 775-788.

Dlugos, D., Shinnar, S., Cnaan, A., Hu, F., Moshe, S., Mizrahi, E., Masur, D., Sogawa, Y., Le Pichon, J.B., Levine, C., et al. (2013). Pretreatment EEG in childhood absence epilepsy: associations with attention and treatment outcome. Neurology 81, 150-156.

Eid, T., Lee, T.W., Patrylo, P., and Zaveri, H.P. (2019). Astrocytes and Glutamine Synthetase in Epileptogenesis. J Neurosci Res 97, 1345-1362.

Ferraro, T.N., Golden, G.T., Smith, G.G., St Jean, P., Schork, N.J., Mulholland, N., Ballas, C., Schill, J., Buono, R.J., and Berrettini, W.H. (1999). Mapping loci for pentylenetetrazol-induced seizure susceptibility in mice. J Neurosci 19, 6733-6739.

Fogerson, P.M., and Huguenard, J.R. (2016). Tapping the Brakes: Cellular and Synaptic Mechanisms that Regulate Thalamic Oscillations. Neuron 92, 687-704.

Funfschilling, U., Supplie, L.M., Mahad, D., Boretius, S., Saab, A.S., Edgar, J., Brinkmann, B.G., Kassmann, C.M., Tzvetanova, I.D., Mobius, W., et al. (2012). Glycolytic oligodendrocytes maintain myelin and long-term axonal integrity. Nature 485, 517-521.

Geraghty, A.C., Gibson, E.M., Ghanem, R.A., Greene, J.J., Ocampo, A., Goldstein, A.K., Ni, L., Yang, T., Marton, R.M., Pasca, S.P., et al. (2019). Loss of Adaptive Myelination Contributes to Methotrexate Chemotherapy-Related Cognitive Impairment. Neuron. 
1012 Gibson, E.M., Nagaraja, S., Ocampo, A., Tam, L.T., Wood, L.S., Pallegar, P.N., Greene, J.J., Geraghty, A.C., Goldstein, A.K., Ni, L., et al. (2019). Methotrexate Chemotherapy Induces Persistent Tri-glial Dysregulation that Underlies Chemotherapy-Related Cognitive Impairment. 1015 Cell 176, 43-55 e13.

1016 Gibson, E.M., Purger, D., Mount, C.W., Goldstein, A.K., Lin, G.L., Wood, L.S., Inema, I., Miller, S.E., Bieri, G., Zuchero, J.B., et al. (2014). Neuronal activity promotes oligodendrogenesis and adaptive myelination in the mammalian brain. Science $344,1252304$.

Gross, D.W. (2011). Diffusion tensor imaging in temporal lobe epilepsy. Epilepsia 52 Supp/ 4, 32-34.

1021 Guilhoto, L.M. (2017). Absence epilepsy: Continuum of clinical presentation and epigenetics? Seizure 44, 53-57.

Hartmann, M., Heumann, R., and Lessmann, V. (2001). Synaptic secretion of BDNF after highfrequency stimulation of glutamatergic synapses. EMBO J 20, 5887-5897.

Hines, J.H., Ravanelli, A.M., Schwindt, R., Scott, E.K., and Appel, B. (2015). Neuronal activity biases axon selection for myelination in vivo. Nat Neurosci 18, 683-689.

Holmes, M.D., Brown, M., and Tucker, D.M. (2004). Are "generalized" seizures truly generalized? Evidence of localized mesial frontal and frontopolar discharges in absence. Epilepsia 45, 1568-1579. balance growth with self-repulsion to achieve homeostasis in the adult brain. Nat Neurosci 16, 668-676.

Hughes, E.G., Orthmann-Murphy, J.L., Langseth, A.J., and Bergles, D.E. (2018). Myelin cortex. Nat Neurosci 21, 696-706. Reciprocal inhibitory connections and network synchrony in the mammalian thalamus. Science 283, 541-543. th, J.L. Noebels, M. Avoli, M.A. Rogawski, R.W. Olsen, and A.V. Delgado-Escueta, eds. (Bethesda (MD)). stimulation-evoked responses in rat somatosensory thalamic neurons in vitro. J Neurophysiol $77,2661-2676$.

Kowianski, P., Lietzau, G., Czuba, E., Waskow, M., Steliga, A., and Morys, J. (2018). BDNF: A Key Factor with Multipotent Impact on Brain Signaling and Synaptic Plasticity. Cell Mol Neurobiol 38, 579-593. 
Larson, V.A., Mironova, Y., Vanderpool, K.G., Waisman, A., Rash, J.E., Agarwal, A., and Bergles, D.E. (2018). Oligodendrocytes control potassium accumulation in white matter and seizure susceptibility. Elife 7 . G., Russo, E., and Citraro, R. (2019). Antiepileptogenic effects of Ethosuximide and Levetiracetam in WAG/Rij rats are only temporary. Pharmacol Rep 71, 833-838. D.M., Nestler, E.J., et al. (2012). Impaired adult myelination in the prefrontal cortex of socially isolated mice. Nat Neurosci 15, 1621-1623. lacking the pacemaker channel HCN2. EMBO J 22, 216-224. experience-dependent oligodendrocyte maturation and myelination. Science 337, 1357-1360. A., and Huguenard, J.R. (2017). Regulation of Thalamic and Cortical Network Synchrony by Scn8a. Neuron 93, 1165-1179 e1166. Pascual, J.M. (2012). Glut1 deficiency (G1D): epilepsy and metabolic dysfunction in a mouse model of the most common human phenotype. Neurobiol Dis 48, 92-101. subnetworks revealed by event-related independent components analysis of functional magnetic resonance imaging. Epilepsia 54, 801-808. advances in childhood absence epilepsy. Pediatr Neurol 50, 205-212. Orban, G., Lambert, R.C., Di Giovanni, G., et al. (2018). Cortical drive and thalamic feedforward inhibition control thalamic output synchrony during absence seizures. Nat Neurosci 21 , 744-756.

1080 McKenzie, I.A., Ohayon, D., Li, H., de Faria, J.P., Emery, B., Tohyama, K., and Richardson,

McCormick, D.A., and Contreras, D. (2001). On the cellular and network bases of epileptic seizures. Annu Rev Physiol 63, 815-846.

1084 W.D. (2014). Motor skill learning requires active central myelination. Science 346, 318-322.

\section{Meeren, H.K., Pijn, J.P., Van Luijtelaar, E.L., Coenen, A.M., and Lopes da Silva, F.H. (2002).} Cortical focus drives widespread corticothalamic networks during spontaneous absence seizures in rats. J Neurosci 22, 1480-1495. 
1085

1086

1087

1088

1089

1090

1091

1092

1093

1094

1095

1096

1097

1098

1099

1100

1101

1102

1103

1104

1105

1106

1107

1108

1109

1110

1111

1112

1113

1114

1115

1116

1117

1118

1119

1120

1121

Mensch, S., Baraban, M., Almeida, R., Czopka, T., Ausborn, J., El Manira, A., and Lyons, D.A. (2015). Synaptic vesicle release regulates myelin sheath number of individual oligodendrocytes in vivo. Nat Neurosci $18,628-630$.

Meyer, J., Maheshwari, A., Noebels, J., and Smirnakis, S. (2018). Asynchronous suppression of visual cortex during absence seizures in stargazer mice. Nat Commun 9, 1938.

Miron, V.E., Boyd, A., Zhao, J.W., Yuen, T.J., Ruckh, J.M., Shadrach, J.L., van Wijngaarden, P., Wagers, A.J., Williams, A., Franklin, R.J.M., et al. (2013). M2 microglia and macrophages drive oligodendrocyte differentiation during CNS remyelination. Nat Neurosci 16, 1211-1218.

Mishra, A.M., Bai, X., Motelow, J.E., Desalvo, M.N., Danielson, N., Sanganahalli, B.G., Hyder, F., and Blumenfeld, H. (2013). Increased resting functional connectivity in spike-wave epilepsy in WAG/Rij rats. Epilepsia 54, 1214-1222.

Mitew, S., Gobius, I., Fenlon, L.R., McDougall, S.J., Hawkes, D., Xing, Y.L., Bujalka, H., Gundlach, A.L., Richards, L.J., Kilpatrick, T.J., et al. (2018). Pharmacogenetic stimulation of neuronal activity increases myelination in an axon-specific manner. Nature communications 9 , 306.

Moeller, F., LeVan, P., Muhle, H., Stephani, U., Dubeau, F., Siniatchkin, M., and Gotman, J. (2010). Absence seizures: individual patterns revealed by EEG-fMRI. Epilepsia 51, 2000-2010.

Morse, E., Giblin, K., Chung, M.H., Dohle, C., Berg, A.T., and Blumenfeld, H. (2019). Historical trend toward improved long-term outcome in childhood absence epilepsy. Epilepsy Res 152, 710.

Mount, C.W., Yalcin, B., Cunliffe-Koehler, K., Sundaresh, S., and Monje, M. (2019).

Monosynaptic tracing maps brain-wide afferent oligodendrocyte precursor cell connectivity. Elife 8.

Musgrave, J., and Gloor, P. (1980). The role of the corpus callosum in bilateral interhemispheric synchrony of spike and wave discharge in feline generalized penicillin epilepsy. Epilepsia 21, 369-378.

Nagy, B., Hovhannisyan, A., Barzan, R., Chen, T.J., and Kukley, M. (2017). Different patterns of neuronal activity trigger distinct responses of oligodendrocyte precursor cells in the corpus callosum. PLoS Biol 15, e2001993.

Nave, K.A. (2010). Myelination and the trophic support of long axons. Nat Rev Neurosci 11, 275-283.

Nersesyan, H., Hyder, F., Rothman, D.L., and Blumenfeld, H. (2004). Dynamic fMRI and EEG recordings during spike-wave seizures and generalized tonic-clonic seizures in WAG/Rij rats. J Cereb Blood Flow Metab 24, 589-599.

Noori, R., Park, D., Griffiths, J.D., Bells, S., Frankland, P.W., Mabbott, D., and Lefebvre, J. (2020). Activity-dependent myelination: A glial mechanism of oscillatory self-organization in large-scale brain networks. Proc Natl Acad Sci U S A 117, 13227-13237. 
1122 Pack, A.M. (2019). Epilepsy Overview and Revised Classification of Seizures and Epilepsies.

1123 Continuum (Minneap Minn) 25, 306-321.

1124 Pajevic, S., Basser, P.J., and Fields, R.D. (2014). Role of myelin plasticity in oscillations and synchrony of neuronal activity. Neuroscience 276, 135-147.

1126 Pan, S., Mayoral, S.R., Choi, H.S., Chan, J.R., and Kheirbek, M.A. (2020). Preservation of a remote fear memory requires new myelin formation. Nat Neurosci 23, 487-499.

1128 Papale, L.A., Beyer, B., Jones, J.M., Sharkey, L.M., Tufik, S., Epstein, M., Letts, V.A., Meisler, M.H., Frankel, W.N., and Escayg, A. (2009). Heterozygous mutations of the voltage-gated sodium channel SCN8A are associated with spike-wave discharges and absence epilepsy in mice. Hum Mol Genet 18, 1633-1641.

1132 Papandrea, D., Anderson, T.M., Herron, B.J., and Ferland, R.J. (2009). Dissociation of seizure traits in inbred strains of mice using the flurothyl kindling model of epileptogenesis. Exp Neurol $215,60-68$.

Paz, J.T., Bryant, A.S., Peng, K., Fenno, L., Yizhar, O., Frankel, W.N., Deisseroth, K., and Huguenard, J.R. (2011). A new mode of corticothalamic transmission revealed in the Gria4(-/-) model of absence epilepsy. Nat Neurosci 14, 1167-1173.

Pietrobon, D. (2002). Calcium channels and channelopathies of the central nervous system. Mol Neurobiol 25, 31-50.

1140 Pitkanen, A., Lukasiuk, K., Dudek, F.E., and Staley, K.J. (2015). Epileptogenesis. Cold Spring Harb Perspect Med 5.

Polack, P.O., Guillemain, I., Hu, E., Deransart, C., Depaulis, A., and Charpier, S. (2007). Deep layer somatosensory cortical neurons initiate spike-and-wave discharges in a genetic model of absence seizures. J Neurosci 27, 6590-6599.

1145 Russo, E., Citraro, R., Constanti, A., Leo, A., Luttjohann, A., van Luijtelaar, G., and De Sarro, G. (2016). Upholding WAG/Rij rats as a model of absence epileptogenesis: Hidden mechanisms and a new theory on seizure development. Neurosci Biobehav Rev 71, 388-408.

1148 Sarkisova, K.Y., Kuznetsova, G.D., Kulikov, M.A., and van Luijtelaar, G. (2010). Spike-wave discharges are necessary for the expression of behavioral depression-like symptoms. Epilepsia $51,146-160$.

1151 Schevon, C.A., Weiss, S.A., McKhann, G., Jr., Goodman, R.R., Yuste, R., Emerson, R.G., and Trevelyan, A.J. (2012). Evidence of an inhibitory restraint of seizure activity in humans. Nat Commun 3, 1060.

1154 Scicchitano, F., van Rijn, C.M., and van Luijtelaar, G. (2015). Unilateral and Bilateral Cortical Resection: Effects on Spike-Wave Discharges in a Genetic Absence Epilepsy Model. PLoS One 10, e0133594.

1157 Seo, S., and Leitch, B. (2014). Altered thalamic GABAA-receptor subunit expression in the 
Sharma, P., Wright, D.K., Johnston, L.A., Powell, K.L., Wlodek, M.E., Shultz, S.R., O'Brien, T.J., and Gilby, K.L. (2017). Differences in white matter structure between seizure prone (FAST) and seizure resistant (SLOW) rat strains. Neurobiol Dis 104, 33-40.

1162 Shinnar, R.C., Shinnar, S., Cnaan, A., Clark, P., Dlugos, D., Hirtz, D.G., Hu, F., Liu, C., Masur, D., Weiss, E.F., et al. (2017). Pretreatment behavior and subsequent medication effects in childhood absence epilepsy. Neurology 89, 1698-1706.

Sorokin, J.M., Davidson, T.J., Frechette, E., Abramian, A.M., Deisseroth, K., Huguenard, J.R., and Paz, J.T. (2017). Bidirectional Control of Generalized Epilepsy Networks via Rapid RealTime Switching of Firing Mode. Neuron 93, 194-210.

1168 Steadman, P.E., Xia, F., Ahmed, M., Mocle, A.J., Penning, A.R.A., Geraghty, A.C., Steenland, H.W., Monje, M., Josselyn, S.A., and Frankland, P.W. (2020). Disruption of Oligodendrogenesis Impairs Memory Consolidation in Adult Mice. Neuron 105, 150-164 e156.

Steriade, M., Amzica, F., Neckelmann, D., and Timofeev, I. (1998). Spike-wave complexes and fast components of cortically generated seizures. II. Extra- and intracellular patterns. J Neurophysiol 80, 1456-1479.

Steriade, M., and Contreras, D. (1998). Spike-wave complexes and fast components of cortically generated seizures. I. Role of neocortex and thalamus. J Neurophysiol 80, 1439-1455.

Stevens, B., Tanner, S., and Fields, R.D. (1998). Control of myelination by specific patterns of neural impulses. J Neurosci 18, 9303-9311.

1180 Tangwiriyasakul, C., Perani, S., Centeno, M., Yaakub, S.N., Abela, E., Carmichael, D.W., and

Swire, M., Kotelevtsev, Y., Webb, D.J., Lyons, D.A., and Ffrench-Constant, C. (2019). Endothelin signalling mediates experience-dependent myelination in the CNS. Elife 8.

1183 Tenney, J.R., Fujiwara, H., Horn, P.S., Jacobson, S.E., Glauser, T.A., and Rose, D.F. (2013). Richardson, M.P. (2018). Dynamic brain network states in human generalized spike-wave discharges. Brain 141, 2981-2994. Focal corticothalamic sources during generalized absence seizures: a MEG study. Epilepsy Res 106, 113-122.

Tomassy, G.S., Berger, D.R., Chen, H.H., Kasthuri, N., Hayworth, K.J., Vercelli, A., Seung, H.S., Lichtman, J.W., and Arlotta, P. (2014). Distinct profiles of myelin distribution along single axons of pyramidal neurons in the neocortex. Science $344,319-324$.

1189 Truccolo, W., Donoghue, J.A., Hochberg, L.R., Eskandar, E.N., Madsen, J.R., Anderson, W.S., 1190 Brown, E.N., Halgren, E., and Cash, S.S. (2011). Single-neuron dynamics in human focal 1191 epilepsy. Nat Neurosci 14, 635-641.

1192 van Luijtelaar, G., Mishra, A.M., Edelbroek, P., Coman, D., Frankenmolen, N., Schaapsmeerders, P., Covolato, G., Danielson, N., Niermann, H., Janeczko, K., et al. (2013). absence model. Neurobiol Dis 60, 126-138. 
van Luijtelaar, G., and Sitnikova, E. (2006). Global and focal aspects of absence epilepsy: the contribution of genetic models. Neurosci Biobehav Rev 30, 983-1003.

1198 Vergnes, M., Marescaux, C., Lannes, B., Depaulis, A., Micheletti, G., and Warter, J.M. (1989). Interhemispheric desynchronization of spontaneous spike-wave discharges by corpus callosum transection in rats with petit mal-like epilepsy. Epilepsy Res 4, 8-13.

1201 Verrotti, A., Matricardi, S., Rinaldi, V.E., Prezioso, G., and Coppola, G. (2015). Neuropsychological impairment in childhood absence epilepsy: Review of the literature. J Neurol Sci 359, 59-66.

Vezzani, A., Balosso, S., and Ravizza, T. (2019). Neuroinflammatory pathways as treatment targets and biomarkers in epilepsy. Nat Rev Neurol 15, 459-472.

1206 Vezzani, A., French, J., Bartfai, T., and Baram, T.Z. (2011). The role of inflammation in epilepsy. Nat Rev Neurol 7, 31-40.

1208 von Krosigk, M., Bal, T., and McCormick, D.A. (1993). Cellular mechanisms of a synchronized oscillation in the thalamus. Science $261,361-364$. computational neuroanatomy: from morphometry to in-vivo histology. Curr Opin Neurol 28, 313322.

1213 Williams, D. (1953). A study of thalamic and cortical rhythms in petit mal. Brain 76, 50-69.

Wirrell, E.C. (2003). Natural history of absence epilepsy in children. Can J Neurol Sci 30, 184188. prognosis of typical childhood absence epilepsy: remission or progression to juvenile myoclonic epilepsy. Neurology 47, 912-918.

Wu, M., Hernandez, M., Shen, S., Sabo, J.K., Kelkar, D., Wang, J., O'Leary, R., Phillips, G.R., Cate, H.S., and Casaccia, P. (2012). Differential modulation of the oligodendrocyte transcriptome by sonic hedgehog and bone morphogenetic protein 4 via opposing effects on histone acetylation. J Neurosci 32, 6651-6664.

Xiao, L., Ohayon, D., McKenzie, I.A., Sinclair-Wilson, A., Wright, J.L., Fudge, A.D., Emery, B., $\mathrm{Li}, \mathrm{H}$., and Richardson, W.D. (2016). Rapid production of new oligodendrocytes is required in the earliest stages of motor-skill learning. Nat Neurosci 19, 1210-1217.

1229 Yang, T., Guo, Z., Luo, C., Li, Q., Yan, B., Liu, L., Gong, Q., Yao, D., and Zhou, D. (2012).

1230 White matter impairment in the basal ganglia-thalamocortical circuit of drug-naive childhood 1231 absence epilepsy. Epilepsy Res 99, 267-273.

Xin, W., Mironova, Y.A., Shen, H., Marino, R.A.M., Waisman, A., Lamers, W.H., Bergles, D.E., and Bonci, A. (2019). Oligodendrocytes Support Neuronal Glutamatergic Transmission via Expression of Glutamine Synthetase. Cell Rep 27, 2262-2271 e2265. 
1232 Zonouzi, M., Berger, D., Jokhi, V., Kedaigle, A., Lichtman, J., and Arlotta, P. (2019). Individual 1233 Oligodendrocytes Show Bias for Inhibitory Axons in the Neocortex. Cell Rep 27, 2799-2808 1234 e2793.

1235

1236 